\title{
Dynamic response of laminated composites using design of experiments: An experimental and numerical study
}

\author{
Luiz Fernando dos Santos Souza ${ }^{1}$, Dirk Vandepitte ${ }^{2}$, Volnei Tita ${ }^{3}$, Ricardo de Medeiros ${ }^{1}$ \\ ${ }^{I}$ Department of Mechanical Engineering, Santa Catarina State University, Rua Paulo Malschitzki, 200 - Zona \\ Industrial Norte, 89219-710, Joinville, SC, Brazil. \\ ${ }^{2} K U$ Leuven, Department of Mechanical Engineering, Celestijnenlaan 300B, Heverlee, B-3001, Belgium. \\ ${ }^{3}$ Department of Aeronautical Engineering, São Carlos School of Engineering, University of São Paulo, Av. João \\ Dagnone, 1100, 13573-120, São Carlos, SP, Brazil.
}

\begin{abstract}
In addition to many advantages, composite materials constitute a new challenge in many industrial fields and applications. Vibration Based Methods (VBM) are relatively simple and at low cost to detect damage and fails in composite structures, but they are sensitive to variations in geometry and material properties. Recently, the main challenge in VBM is to establish a robust process to be applied on an industrial environment. In this work, a methodology to identify the effect of design parameters on the dynamic response of laminated composite plates is presented. For the case of composite materials, the production process plays an important role. Numerical dynamic analyses are run using the Finite Element code ABAQUS ${ }^{\mathrm{TM}}$, which is complemented with user subroutines written in Fortran and Python. A Design of Experiments (DoE) strategy is developed to reduce the number of experiments and to evaluate the effect of the design parameters. In this work, two sets of composite plates were evaluated, $[0]_{8}$ and $[0 /-15 / 15 / 0 /-15 / 15]_{s}$, with natural frequencies used as response quantities. In addition, Frequency Response Functions are analysed, as they are obtained by a full factorial design. Afterwards, the results are discussed with proper attention for the potential and for the limitations of the proposed methodology from the perspective of usage to detect damage and failure in composite structures.
\end{abstract}

Keywords: Dynamic Response; Design of Experiments; Composite Materials, Finite Element Analysis.

\footnotetext{
* Corresponding author: Phone +5547 3481-7645

E-mail address: ricardo.medeiros@udesc.br (Ricardo de Medeiros)
} 


\section{Introduction}

Many industrial applications require a good understanding of the structural integrity to prevent accidents and to improve the maintenance program. Most structures tend to degrade over time, with a negative effect on material properties due to different sources like environmental conditions and accidental events. Imperfect design and manufacturing imperfections inevitably introduce uncertainty into the system, which adds to the complexity of accurate modelling. Methodologies and systems to detect damage on the structure in an early stage, and to evaluate its severity are useful to avoid structural failure. As listed by Adams [1], structural damage may have different sources like micro-structural defects, corrosion, residual stress, cracking, fastener faults, adhesive faults, and other types of instabilities. Damage changes structural behaviour. Further, it is necessary to inspect the structure periodically to maintain the safety and reliability of the component. This is the reason why it is possible to find several non-destructive techniques (NDT) for the identification of damage in a structure [2].

Successful damage detection in structures is essential for maintenance. NDE/NDT, which can identify damage, may be used for this purpose. However, most of the nondestructive methods, such as ultrasonic methods, require the location of the damage and that location must be accessible. The methods, which are based on vibration responses (VBM), usually do not show these limitations. The basis of vibration response methods is that damage changes the dynamic behaviour of the structure. Damage in a structure can alter the structural integrity, and therefore, the physical properties like stiffness, mass and/or damping may change, modifying the global structural dynamic response. The dynamic behaviour of a structure is a function of these physical properties and will, therefore, directly be affected by the damage. The dynamic behaviour can be described by time, frequency and modal domain parameters. The changes in these parameters (or properties derived from these parameters) are used as damage indicators. Ooijevaar [3] has categorised the vibration based methods according to their damage sensitive feature and statistical classifier.

Commonly, when damage develops in a structure, the stiffness decreases and, consequently a reduction of some natural frequencies of the system can be observed. This hypothesis is used for many methods based on natural frequency analysis. A remarkable advantage of this detection technique is that frequency measurements can be conducted quickly and easily. This approach can identify the presence of the damage and, in some cases, the location [4-14]. Several methods and metrics have been proposed by the present authors in 
previous works in order to improve the detection of damage in composite structures, some of them are used in conjunction with numerical models and analysis to support the damage study, mainly via VBM. Sartorato et al. [15] presented a new shell finite element model based on a modified First Order Shear Theory (FOST) for piezoelectric composite laminates, to simulate thin structures with piezoelectric sensors via VBM. In addition, De Medeiros et al. [16] presented a combination of a vibration-based method and speckle shearography to identify, locate and quantify the damage in composite structures. A new damage metric and a Frequency Response Functions (FRF) based method are used to identify damage in a first approach and an optical interferometric technique locates and quantifies the extent of damage in the structure. Additionally, De Medeiros et al. [17] proposed a new damage metric taking into account not only the amplitude, but also the phase of the FRF. The new metric was compared with other ones and experimental data, concluding that vibration-based metrics are a good option not only to identify the damage, but also to provide a prediction of the damage severity [18].

However, small variations on material and/or geometric parameters can also change the natural frequencies. These deviations from the nominal configuration pose challenges for establishing the reference structure (undamaged structure) to be compared to others (damaged structures). A relevant issue in VBM is the difficulty to know the nominal characteristics of the manufactured component, since the manufacturing process may have a significant effect on material values. The commonly used procedure is to acquire data from the manufactured component just after fabrication, and use it as a reference value to identify damage. However, for some kinds of damage, it is not possible to evaluate the same manufactured component before and after the incidence of damage. It is important to know the influence of each design variable on the dynamic response to create models and define better quality criteria for the manufacturing process. One way to approach this problem consists of applying a design of experiments methodology (DoE), which is a powerful tool for the identification of the influence of the most important process parameters in the structural response [19]. Kleijnen [20] lists different methodologies that may be useful. A second advantage of DoE is to provide more information than one-change-at-a-time traditional experimental methods. In fact, DoE methods allows to measure the significance of the design variables not only when they are acting alone, but also when combined effects are present. Computational simulations and DoE have shown to be an important tool for complex analyses and parameter optimisation. It opens the possibility to improve the search by optimal parameters, and evaluates the influence of variables in a process [21-24]. 
Based on the knowledge of the authors, in the literature, it is common to find methodologies to analyse only the damage response in composite structures. Thus, considering the scenario pointed above, this work aims to contribute to the development a new methodology, for manufacturing process verification, based on the dynamic response (VBM) to be applied on composite structures. In addition, the proposed methodology takes into account the most important design parameters, to determine a range of frequency to be considered, via vibration analysis regarding manufacturing process effects of composite structures. Also, a detailed description of the methodology analysis, considering the influence of the design variables in each mode shape is presented. Several experiments are required to cover the entire design space to evaluate the process. In addition, computational analysis is used to reduce the cost, in conjunction with a DoE strategy. Also, a detailed description of the methodology analysis, considering the influence of the design variables in each mode shape is presented. An expected range for the dynamic response is defined. In this case study, the four most significant parameters are identified among eleven variables of the composite plates. The variables include geometry parameters (width, length, central distance, ply orientation and thickness) as well as material parameters (Young's modulus in fibre and in transverse direction, shear modulus in ply plane and Poisson's ratio). These parameters are obtained from the experimental analysis of carbon fibre reinforced epoxy plates. Numerical analysis is performed by Finite Element Method to predict the modal parameters. First, free vibration analyses were carried out to find the natural frequencies. Afterwards, the set of Frequency Response Functions (FRFs) obtained from the variation of the most significant parameters are compared to the experimental ones. This comparison shows the influence of the range of parameters due to the manufacturing process on the dynamic response. Finally, there is a discussion on damage detection by VBM.

\section{Methodology}

Figure 1 summarizes the analysis steps, which are done in this work. In a first step, variability of the design variables is quantified (1). Design variables related to the geometry of the composite plates are evaluated using 3D scanning (2), and variables related to the materials properties were obtained by literature reference (3). The range of the design variables is important input for the DoE procedure.

The second step is the execution of numerical simulations, based on the interval values of the design variables. Numerical modal analysis (4) runs using software ABAQUS ${ }^{\mathrm{TM}}$ in order 
to obtain the results of the configurations as defined in the DoE plan. The DoE process not only allow to have an approximation of the influence of each individual design variable (5) on each mode of the structure, but it also gives a ranking of the importance of each parameter (6). Experimental modal analysis (7) of the intact (undamaged) plates is used as baseline for the numerical simulation. An impact test (8), using an impact machine based on a drop mass system, were carried out to analyse the influence of the damage on the modal frequencies. CScan (9) and modal analysis experiments of intact (undamaged) and damaged plates provide independent validation, showing the damage type and the influence of this damage on each mode.

In a last step, a full factorial design (10) was applied, however restricted to the four most important design variables, to obtain the FRFs using numerical simulations. The numerical results are used to create an envelope that characterises the set of composite plates evaluated in the DoE process. The envelope generated by numerical and experimental FRFs are compared, and the results are commented in the conclusions.

\section{Experimental analyses}

\subsection{D Scanning and materials properties analyses}

To conduct the DoE process, the upper and lower limit of the design variables should to be defined. Using experimental data to define these boundaries it is possible to improve the quality of the DoE representation. Fourteen carbon fibre with epoxy resin (Carbon Fibre Reinforced Polymer - CFRP) composite plates are manufactured by filament winding (Fig. 2), with nominal length of $305 \mathrm{~mm}$ and nominal width of $245 \mathrm{~mm}$.

Two configurations are used: 8 unidirectional plies $[0]_{8}$ at a total thickness of about 2.2 $\mathrm{mm}$ and a 12 ply [0/-15/15/0/-15/15]s stacking sequence at a total thickness of $3.3 \mathrm{~mm}$. These two stack sequence configurations were chosen due the limitations of the manufacturing process, since the maximum angle allowed is $\pm 15^{\circ}$. The fibres are impregnated with resin before winding (wet winding). A parallelepiped shape mandrel (Fig. 2(a)) is used in the winding process, and almost flat plates are cut from the four sides after demoulding the wound part (Fig. 2(b)). This process produces laminate plates with high quality. The plates are then cured in a controlled oven. Depending on the stacking sequence of the laminate, almost flat plates are obtained with a small single curvature, which is caused by residual internal stress. 
Geometry data are obtained using a 3D optical scanner and the results for each individual plate are listed in Table 1. Here, the thickness values of each plate, were obtained using the average of measured points (around 325000 points) from the $3 \mathrm{D}$ optical scanning (Figure 3).

Statistics on plate geometry data are summarized in Table 2. It shows the variability of the thickness in the manufacturing process. The maximum and minimum values of width $(\mathrm{W})$, length (L) and central distances $(\mathrm{C} 1, \mathrm{C} 2)$ are taken (Fig. 4). The curvature has the shape of a circular arc, with $\mathrm{C} 1$ and $\mathrm{C} 2$ the maximum distance from the plate to the horizontal reference line. The difference on central distances between the two sides of the plate, $\mathrm{C} 1$ and $\mathrm{C} 2$, can be explained due residual stress provide by the curing process and the variation of the total thickness of the plate. The upper and lower values for thickness were obtained evaluating the distribution provided by the 3D scanner. Where a normal distribution has been observed. Therefore, the upper and lower values for the thickness range was defined in a way that, $99.7 \%$ of the measured values were into these boundaries. The median shown in Table 2 is the median between plates.

Experimental data of the plate material properties has been not possible to acquire directly, due to the classified information about the manufacturing process. However, to aid the readers for understanding the mechanical behaviour of composite material, the values used in this paper comes from researches with similar material. Tita et al. [25] and Ribeiro et al. [26] have investigated similar materials and obtained experimentally material properties, which is assumed as baseline for this paper (Table 3). In fact, the specimens manufactured and studied by Tita et al. [25] are made from prepreg M10 from $\mathrm{Hexel}^{\mathrm{TM}}$, which are preimpregnated unidirectional carbon fibres by epoxy resin, with a fibre volume ratio of the laminates of $63 \%$. In addition, Tita et al. [25] compared the values obtained by other results present in the literature for the same material. Therefore, to define the levels of materials properties for the DoE process, it was used a min-max range of $\pm 10 \%$ with respect to the baseline values. Parameter ranges are summarized in Table 4 for the $[0]_{8}$ plates, and in Table 5 for the $[0 / 15 /-15 / 0 / 15 /-15 / 0]_{\text {s }}$ plates.

The filament winding manufacture process causes a little deviation on the fibre direction angle, mainly on $[0]_{8}$. It is due the physical impossibility of stacking all fibres at $0^{\circ}$. Therefore, a small deviation based on the fibre diameter was imposed on the DoE process to evaluate the influence of this design variable. 


\subsection{Experimental modal analyses}

An experimental apparatus was prepared to conduct the dynamic analyses of the composite plates. The natural frequencies and FRFs can be obtained in different four points by using four accelerometers attached to the plates in the positions as shown in Figure 5. However, data to detect the damage is provided by only one accelerometer. Hence, only one accelerometer per plate is used to interrogate the flaw only once. The used accelerometer is a model 352A24 (Bruel \& Kjaer) lightweight structure with sensitivity of $102.34 \mathrm{mV} / \mathrm{g}$.

The excitation for both sets of vibration tests is applied using an impulse signal through an impact hammer PCB Model 0860C3 (Piezotronics). The input is applied at the same position of the accelerometer on the back side of the plate (Fig. 5). The set-up used in the experiments consists of a plate suspended by elastomer wires to simulate free-free boundary conditions, whereas accelerometer and the impact hammer are connected to an LMS SCADAS Mobile equipment controlled by the Test.Lab software (LMS Test.Lab) (Fig. 6). The impact hammer excites the panel with a wide frequency spectrum. This is important, because different types of damage can affect different frequency ranges, and the resonant and anti-resonant characteristics of a structure may be good indicators of damage. In this experiment, the lower eight modal frequencies are investigated. The signal consists of 2048 points over the frequency range from 0 to 512 Hertz. The acquisition time is 4 seconds with a resolution of $0.25 \mathrm{~Hz}$.

\subsection{Damage by impact and C-Scan analysis}

In the most general terms, damage can be defined as any change, which has a negative impact on the systems operation, compromising its current and future functioning. Furthermore, Kim et al. [27] defined damage as changes to the material and/or geometric properties of these systems, including changes to the boundary conditions and system connectivity, which adversely affect the current or future performance of these systems. In this research project, damage was introduced into the structure by impact. An impact machine (drop tower) is used to damage all plates [28]. In this machine a mass is dropped from a certain height, hitting the test coupon. The average energy level used for these tests were of the order of 10 Joules for $[0]_{8}$ stacking orientation and 19 Joules for $[0 / 15 /-15 / 0 / 15 /-15 / 0]_{\mathrm{s}}$ stacking orientation plates. The nature and the extent of damage are identified by ultrasonic C-scan, and modal analysis of the damaged structure is used to quantify the severity of the damage. 
The pulse-echo method is the most widely used ultrasonic method as shown by Davis [29]. This method is used for flaw location and thickness measurement. Ultrasonic data can be presented in different formats, which are A-, B-, and C-scan. Echoes from internal reflecting interfaces within an area are recorded by C-scan. The ultrasonic signal amplitude or the timeof-flight is shown as a shade of gray or a colour for each position, which was scanned. Ultrasonic NDE (Non-destructive Evaluation) uses focused acoustic energies that interact with the micro-structure of the material. Water is often used as a coupling medium between the wave source and the material due to its efficiency for transmitting sound energy and for creating a distinct and uniform interface with the material. Acoustic waves are reflected, when they hit a surface or an inclusion with a different density, such as the water/material interface and zones which are affected by internal damage in the material [30]. The resulting feedback includes the variations of wave amplitude and velocity, which are then converted into information regarding the material structure. A C-scan technique is used to obtain the extent of damage in the structures. Figure 7 shows the experimental C-Scan test setup used for the composite plates.

\section{Numerical analyses}

\subsection{Numerical Model}

Finite element models of the laminated composite plates are built in ABAQUS ${ }^{\mathrm{TM}}$ software complemented by Python subroutines. The element type and size were chosen based on previous analyses [31]. Quadrilateral 8-node shell elements are used (defined as S8R5). 5640 elements and 8784 nodes are used to mesh the plate domain, this mesh size $(3 \mathrm{~mm})$ is defined after a refinement analysis to obtain the eight first modes.

A numerical modal analysis procedure identifies the natural frequencies for each configuration, which is defined by the DoE. The numerical analyses are done in a quasi-freefree boundary conditions. Elastic wires have a very low yet non-zero low stiffness $(10 \mathrm{~N} / \mathrm{m})$, as they are attached to the composite plate. The elastic wires are fixed on translation (Ux, Uy, $\mathrm{Uz}$ ) and also on rotations (Urx, Ury, Urz). The excitation is applied in the same position as in the experimental tests (Fig. 8). The accelerometer has a much lower mass than the composite plates, for this reason, no additional mass is included in the numerical analyses.

The damping coefficients have been extracted experimentally from all plates, using the Peak Picking method [32]. Table 6 shows the mean and the standard deviation of the damping coefficients between the plates for each mode, except for modes 7 and 8 of [0/15/-15/0/15/- 
15/0] . Figure 9 shows the mode shapes of the plates, where both stacking sequence have the same mode shape.

\subsection{DOE and modal analyses}

Design of experiments (DoE) is a statistical method, which identifies the most important variables in a process. One of the main features of $\mathrm{DoE}$ is the capacity to find the variables that have high influence in the process, which may be used to reduce the design space. This process is important to simplify models and to reduce the number of experiments needed to represent physical phenomena.

The manufacturing process of a laminated composite plate has many design and process control variables. This study defines a set of 11 variables, which are directly related to the final component and which are taken to be uniform throughout the entire plate: width, length, thickness, fibre angles, two quantities of distances to represent the curvature of the plate (one at each side of the plate), Young's modulus in longitudinal and transverse directions, shear modulus in plane 1-2 and 2-3 and Poisson's ratio. First, a fractional factorial design is applied to identify the main variables, which affect each mode. After that, a screening analysis is conducted to verify the four main variables, which affect the dynamic response. Finally, a full factorial design is used to analyse the parameter effects. In each level of the analysis, each variable has two levels for a total of $2^{11}=2048$ numerical experiments to cover all combinations.

The screening process is conducted throughout two-level Plackett-Burman (P-B) design. This kind of design of experiments has the objective of find an experimental design where each combination of levels for any pair of factors appears the same number of times, throughout all the experimental runs. A complete factorial design would satisfy this criterion, but the idea was to find smaller designs. For the case of two levels P-B, an orthogonal array fills this requirement. The simulations do not introduce noise, so a P-B 12 (i.e. the 12-run Plackett-Burman design L12 Table) is selected (Table 7).

\section{Numerical results and validation}

Numerical analysis runs are conducted to evaluate each combination of parameters presented in the DoE process. The results of the natural frequencies for each numerical run is presented in Figure 10 for stacking sequence of $[0]_{8}$ and the Figure 11 for the stacking sequence of $[0 / 15 /-15 / 0 / 15 /-15 / 0]_{\mathrm{s}}$. Figures 10 and 11 show that the variability of the resulted frequency 
increases with the order of the modes. It means that high modes are more sensitive than lower ones. Therefore, when the objective is to detect small damages, high modes are more strategic to be excited. On the other hand, all other perturbations can influence the results, interfering in the damage detection.

The main effect of each parameter was obtained from the finite element analysis for each natural frequency and calculated as follow:

$$
\text { Main effect }=\operatorname{ME1}(x)-M E 2(x)
$$

where $\operatorname{ME1}(x)$ and $M E 2(x)$ are the mean of the results influenced by level 1 and level 2 of factor $x$, respectively. The main effect is calculated for each mode, and after the total main effect is calculated using the sums of the results from each mode. Parameters are ranked in order of decreasing effect. Table 8 shows the main effect calculated for the results from plates with stacking sequence $[0]_{8}$. Similarly, Table 9 shows the results from plates with stacking sequence $[0 / 15 /-15 / 0 / 15 /-15 / 0]_{s}$.

Tables 8 and 9 show that thickness, the Young's modulus in longitudinal $\left(\mathrm{E}_{11}\right)$ and transverse direction $\left(\mathrm{E}_{22}\right)$ exhibit high influence for both lay-up configurations. This influence is directly related to the mode shape of the plates. For example, mode 2 is a bending mode in the transverse direction, then every change in properties on this direction affect this mode more than others as observed in the numerical results.

Another important remark is related to width and length. Although these parameters are very important in the dynamic response, mainly for the stacking sequence [0/15/-15/0/15/$15 / 0]$ s, they are well controlled during the manufacturing process. In addition, manufacturing parameters, as fibre fraction, which affect directly the materials properties should be carefully monitored in order to keep the materials properties under control. Finally, shear modulus $\left(G_{12}\right)$ is another important parameter to be investigated. The main effect of those four parameters may gives important information for damage detection.

\subsection{Main effect analyses for $[0]_{8}$}

Analysis of the main effect on a mode-by-mode basis for the $[0]_{8}$ plates shows that some design parameters affect more or less the response at some specific modes. For example, it is possible to note that in the $4^{\text {th }}$ mode, the effect of the changes in the $E_{11}(10.66)$ is twice than 
the effect of the thickness (5.46). There is a clear relation between the nature of the mode and the model parameter, which affects the modes most strongly. The Figure 12 vertical axis represents the magnitude of the variable effect on the systems.

Young's modulus is important when bending phenomena dominate the mode and shear modulus is rather related to torsional modes. It is no surprise that the Young's modulus in longitudinal direction is the dominant factor for $4^{\text {th }}$ and $5^{\text {th }}$ modes. In addition, the Young's modulus in the transverse direction show higher influence for $2^{\text {nd }}$ and $6^{\text {th }}$ modes. This behaviour is explained by the modal shapes of the plate.

\subsection{Main effect analyses for $[0 / 15 /-15 / 0 / 15 /-15 / 0]_{\mathrm{s}}$}

The analysis of the main effect on a mode-by-mode basis for the [0/15/-15/0/15/-15/0 $]_{\text {s }}$ plates (Fig. 13) shows different results. Although the highest influence is provided by the thickness, as expected due to the greater number of layers, the $4^{\text {th }}$ mode remains more sensitive to changes in Young's modulus in longitudinal direction, and $2^{\text {nd }}$ and $6^{\text {th }}$ modes remain more sensitive to changes in Young's modulus in transverse direction.

For $[0 / 15 /-15 / 0 / 15 /-15 / 0]_{\text {s }}$ plates, it is observed a more significant effect of $E_{11}$ on $4^{\text {th }}$ and $8^{\text {th }}$ modes. Differently from the $[0]_{8}$ plates, the $5^{\text {th }}$ mode has a lower effect, it is due to the fibre orientations and the mode shape. On the $5^{\text {th }}$ mode there are more nodal lines oriented at 15 degrees, reducing the effect of the Young's modulus in longitudinal direction.

\section{Validation of the numerical results variable influence with experimental data}

In order to evaluate the numerical results obtained and the hypothesis proposed by the main effect analysis, about the influence of each variable, the experimental results obtained via CScan and modal analyses is used to identify the type of the damage as well as the changes on natural frequencies.

\subsection{Experimental results for $[0]_{8}$ plates}

Damage in the plates is identified by C-Scan (Fig. 14). Cracks are observed on the impacted plates at $[0]_{8}$. The natural frequency analysis (Table 10) indicates a high difference between intact and damaged frequency in the $2^{\text {nd }}$ mode, which is strongly affected by changes in $E_{22}$. Changes in $\mathrm{E}_{22}$ can characterize matrix cracks in a unidirectional laminate, and this is confirmed by the C-Scan results. It is important to note that the C-Scan was applied only on the damaged region and not on the whole plate. 
The image of the damaged plate shows a crack propagated on the transverse direction, which reduces the $\mathrm{E}_{22}$ of the material. This effect is remarked on the experimental results as presented in Table 10, where a reduction of $18 \%$ is observed. Also, the numerical results have been indicated the same behaviour, which shows that a reduction in the transversal Young's modulus results in a reduction in the natural frequency.

\subsection{Experimental results for $[0 / 15 /-15 / 0 / 5 /-15]_{\mathrm{s}}$ plates}

The [0/15/-15/0/5/-15 $]_{\mathrm{s}}$ damaged plates natural frequencies do not differ much from the intact plates, because the extent of damage is much more restricted (Table 11). The propagation of a crack in the unidirectional plates is not hindered, whereas the $\pm 15^{\circ}$ orientation of the fibres creates natural barriers for the extent of damages. The C-Scan evaluation of the [0/15/15/0/5/-15] s plates shows a combination of matrix and fibre cracks (Fig. 15). Table 11 shows the relative difference between the intact and damaged plate for the stacking sequence of $[0 / 15 /-15 / 0 / 5 /-15]_{s}$.

\section{Numerical and experimental FRFs}

After the screening study, the four dominant parameters were identified for each arrangement, and they are subsequently used to conduct a full factorial analysis (parameter configuration on Table 12), which is done using the dynamic finite element model. Thus, the FRFs are calculated for each configuration.

Figures 16 and 17 present the numerical FRFs for the stacking sequences $[0]_{8}$ and $[0 / 15 /-15 / 0 / 15 /-15]_{\mathrm{S}}$, respectively. For the unidirectional laminate, the differences between FRFs in low frequencies are smaller and better defined. This observation confirms the wellknown general tendency [39-40] that the sensitivity of dynamic characteristics of a panel increase with frequency. Figures 18 and 19 show the envelope for the numerical and experimental FRFs curves. Envelopes are obtained using the upper and lower values from numerical analyses. The logic behind is based on the following procedure. When the first numerical FRF amplitude starts to increase, it is settled high level for the envelope curve, which has the amplitude equal to the amplitude of the numerical FRF. The envelope level is kept high until the last FRF curve decreases its amplitude.

After constructing the envelopes using the numerical FRFs, it is possible to compare these envelopes with the experimental data. Figures 18 and 19 show that the final envelope 
fits well to the experimental FRFs in the frequency range up to $300 \mathrm{~Hz}$. Those results show the strong influence of the manufacturing process on the dynamic response of composite structures, and it implies the necessity of very robust systems to detect the presence of the damage, since some disturbances from manufacturing systems could cause confusion on sensible damage detection systems. In fact, it is required consistent damage metrics to detect defects in composite structures, i.e. damage metrics need to be stables and robust.

The envelope aforementioned can be used as a methodology to verify if the design variables are into the specification limits, and as a preliminary stage to develop systems for damage detection. This stage can verify the FRF and determines if a more accurate method must be used to identify the damages, or if there is some mode out of the envelope, which implies that a design variable may be out of bounds. Therefore, there are some structural problems as damage or manufacturing issues.

\section{Conclusions}

This paper presents a study of the parameter effect of two composite plates on their dynamic response by using Vibration Based Method. Research is done on a unidirectional laminate and on a laminate with fibre orientations, which deviate from the longitudinal axis. Thus, two sets of intact laminated composite plates with different stacking sequences are analysed numerically and experimentally. A Design of Experiment procedure based on the PlackartBurman design is conducted to screen the main parameters on the process. Natural frequencies, mode shapes and Frequency Response Functions of the composite plates are identified for the lower eight modes. In addition, the experimental natural frequencies for damaged plates (impact damage), and they all are assessed to compare with the undamaged results. In addition, variations on materials properties and geometry due to manufacture process cause significant variations on natural frequencies. The results obtained in the screening design show the most influential parameters such as thickness, Young's modulus in the longitudinal $\left(\mathrm{E}_{11}\right)$ and the transverse direction $\left(\mathrm{E}_{22}\right)$. This work shows that the sensitivity of different modes is influenced by the model parameters. For the dimensions and stacking sequences analysed in this work, the $4^{\text {th }}$ and $5^{\text {th }}$ modes are found to be most sensitive to Young's modulus in longitudinal direction whereas the $2^{\text {nd }}, 6^{\text {th }}$ and $7^{\text {th }}$ modes are most sensitive to Young's modulus in transverse direction, this behaviour can be explained by the modal shape of the plates. 
Furthermore, the envelope created by the numerical FRF results can be used as a tool to estimate the dynamic behaviour of the manufactured components. In a practical application, these envelopes can be used as a quality tool to verify if the component has been properly manufactured in order to guarantee damage detection via VBM. If the experimental analysis of the components indicates that the FRF is out of the envelope bounds, it means that some problem took place during the manufacturing process, and the component is not able to perform its functionality.

Further analyses should be carried out taking in to account the amount of plates in order to define a damage metric, which consider the uncertainties of the manufacture process. The DoE strategy used in this paper show consistent results, as a robust and quickly tool to evaluate the main effect of variables in complex problems. This procedure can be used to define the main parameters to be monitored by a system, and how these parameters can influence the detection process.

\section{Acknowledgements}

The authors acknowledge the financial support of the State Research Founding Agency (FAPESC process number: 1697/2017). As well as, Sao Paulo State Research Foundation (FAPESP process number: 2012/01047-8 and 2015/15221-8), Coordination for the Improvement of the Higher Level Personnel (CAPES process number: 011214/2013-09), National Council for Scientific and Technological Development (CNPq process number: 401170/2014-4 and 310094/2015-1). The authors also would like to thank Navy Technological Centre (CTM - Brazil) for manufacturing specimens and Prof. Joel Martins Crichigno Filho (Santa Catarina State University) for kindly providing the use of the ABAQUS ${ }^{\mathrm{TM}}$ license.

\section{References}

1. Adams, D. Health monitoring of structural materials and components: methods with applications. New York, John Wiley \& Sons, 2007.

2. Fan, W. and Qiao, P. Vibration-based damage identification methods: A review and comparative study. Structural Health Monitoring, 2011(10):83-111.

3. Ooijevaar, T. Vibration based structural health monitoring of composite skin-stiffener structures. PhD thesis, University of Twente, Enschede, Netherlands, 194p, 2014.

4. Doebling SW, Farrar CR, Prime MB. A summary review of vibration-based damage identification methods, Shock and Vibration, 1998(30):91105. 
5. Farrar CR, Doebling SW, Nix DA. Vibration based structural damage identification. Philosophical Transactions of the Royal Society A, 2001(359):131149.

6. Liu CJ, Todd MD, Zheng ZL, Wu Y. A nondestructive method for the pretension detection in membrane structures based on nonlinear vibration response to impact. Structural Health Monitoring, 2017(online version).

7. Xiaokang Y, Hutchins DA. Non-destructive evaluation of composite materials using a capacitive imaging technique. Composites Part B: Engineering, 2012(43):1282-1292.

8. Amenabar I, Mendikute A, Lpez-Arraiza A, Lizaranzu M, Aurrekoetxea J. Comparison and analysis of non-destructive testing techniques suitable for delamination inspection in wind turbine blades. Composites Part B: Engineering, 2011(42):1298-1305.

9. Carden EP and Fanning P. Vibration based condition monitoring: a review. Structural Health Monitoring, 2004(3):355377.

10. Lee YS, Chung MJ. A study on crack detection using eigenfrequency test data. Computers \& Structures, 2000(77):327-342.

11. Kim JT, Ryu YS, Cho HM, Stubbs N. Damage identification in beam-type structures: frequency-based method vs mode-shape-based method. Engineering Structures, 2003(25):5767.

12. Sowjanya C, Sairam NV. Crack Analysis in Beams Using Natural Frequencies through Finite Element Analysis. International Journal of Engineering Technology, Management and Applied Sciences, 2017(06):33-40.

13. Kessler SS, Spearing SM, Atalla MJ, Cesnik CE, Soutis C. Damage detection in composite materials using frequency response methods. Composites Part B: Engineering, 2002(33):8795.

14. Magalhães F, Cunha A, Caetano E. Vibration based structural health monitoring of an arch bridge: From automated OMA to damage detection. Mechanical Systems and Signal Processing, 2012(28):212-228.

15. Sartorato M, De Medeiros R, Vandepitte D, Tita V. Computational model for supporting SHM systems design: Damage identification via numerical analyses. Mechanical Systems and Signal Processing, 2017(84):445-461.

16. De Medeiros R, Lopez H, Guedes R, Vaz M, Vandepitte D, Tita V. A new approach for SHM system: Combination of vibration based method and shearography speckle. In: $5^{\text {th }}$ International Symposium on Solid Mechanics (MecSol2015), Belo Horizonte, Brazil, 2015.

17. De Medeiros R, Lopez H, Guedes R, Vaz M, Vandepitte D, Tita V. A New Methodology for Structural Health Monitoring Applications. Procedia Engineering, 2015(114):54-61.

18. De Medeiros R, Vandepitte D, Tita V. Structural health monitoring for impact damaged composite: a new methodology based on a combination of techniques. Structural Health Monitoring, 2017(online version).

19. Gunasegaram DR, Farnsworth DJ, Nguyen TT. Identification of critical factors affecting shrinkage porosity in permanent mold casting using numerical simulations based on design of experiments. Journal of Materials Processing Technology, 2009(209):1209-1219.

20. Kleijnen JP. An overview of the design and analysis of simulation experiments for sensitivity analysis. European Journal of Operational Research, 2005(164):287-300.

21. Chen VC, Tsui KL, Barton RR, Meckesheimer M. A review on design, modeling and applications of computer experiments. IIE Transactions, 2006(38):273-291.

22. Coleman DE, Montgomery DC. A systematic approach to planning for a designed industrial experiment. Technometrics, 1993(35):1-12. 
23. Bursztyn D, Steinberg DM. Comparison of designs for computer experiments. Journal of Statistical Planning and Inference, 2006(136):1103-1119.

24. Ilzarbe L, lvarez MJ, Viles E, Tanco M. Practical applications of design of experiments in the field of engineering: a bibliographical review. Quality and Reliability Engineering International, 2008(24):417-428.

25. Tita V, De Carvalho J, Vandepitte D. Failure analysis of low velocity impact on thin composite laminates: Experimental and numerical approaches. Composite Structures, 2008(83):413-428.

26. Ribeiro ML, Tita V, Vandepitte D. A new damage model for composite laminates. Composite Structures, 2012(94):635-642.

27. Kim T, Ryu YS, Cho HM, Stubbs N. Damage identification in beam-type structures: Frequency-based method vs mode-shape-based method. Engineering Structures, 2003(25):5767.

28. De Medeiros, Ricardo. Development of a criterion for predicting residual strength of composite structures damaged by impact loading. 2016. PhD Thesis. University of Sao Paulo.

29. Davis JR. ASM Handbook: Non-destructive evaluation and quality control (Vol. 17). ASTM International. 1989.

30. Hassen AA, Boyd J, Vaidya UK. Development of Ultrasonic C-Scan System. ASTM Journal, 2012.

31. Borges EN. Fabricação, Análise Experimental e Computacional de Juntas Híbridas Coladas Monitoradas por Compósitos Inteligentes. Dissertação. São Carlos: University of São Paulo.

32. Ren W, and Zong Z. Output-only modal parameter identification of civil engineering structures. Structural Engineering and Mechanics, 2004(17):429-444.

33. Desmet W, Van Hal B, Sas P, Vandepitte D. A computationally efficient prediction technique for the steady-state dynamic analysis of coupled vibro-acoustic systems. Advances in Engineering Software, 2002(33):527-540.

34. Moens D, Vandepitte D. Fuzzy finite element method for frequency response function analysis of uncertain structures. AIAA Journal, 2002(40):126-136. 
Table 1. Geometric data collected from composite plates, where $\mathrm{C} 1$ and $\mathrm{C} 2$ are the central distance of the plates to the reference plane $[0]_{8}$

\begin{tabular}{|c|c|c|c|c|c|c|}
\hline Plate & $\begin{array}{c}\text { Length } \\
(\mathbf{m m})\end{array}$ & $\begin{array}{c}\text { Width } \\
(\mathbf{m m})\end{array}$ & $\begin{array}{c}\text { Thickness } \\
(\mathbf{m m})\end{array}$ & Stacking sequence & $\begin{array}{c}\text { C1 } \\
(\mathbf{m m})\end{array}$ & $\begin{array}{c}\text { C2 } \\
(\mathbf{m m})\end{array}$ \\
\hline P01 & 305.00 & 245.00 & 2.247 & {$[0]_{8}$} & 3.924 & 3.219 \\
\hline P02 & 305.39 & 244.86 & 2.245 & {$[0]_{8}$} & 3.959 & 3.666 \\
\hline P03 & 305.39 & 244.71 & 2.257 & {$[0]_{8}$} & 4.111 & 4.324 \\
\hline P04 & 305.00 & 245.00 & 2.246 & {$[0]_{8}$} & 3.923 & 4.319 \\
\hline P05 & 304.90 & 245.67 & 2.207 & {$[0]_{8}$} & 3.337 & 4.816 \\
\hline P06 & 304.94 & 246.12 & 2.218 & {$[0]_{8}$} & 3.686 & 4.639 \\
\hline P07 & 305.30 & 245.79 & 2.208 & {$[0]_{8}$} & 3.880 & 4.639 \\
\hline P08 & 303.84 & 245.88 & 2.212 & {$[0]_{8}$} & 3.923 & 4.765 \\
\hline P09 & 306.64 & 247.45 & 3.331 & {$[0 / 15 /-15 / 0 / 15 /-15]_{\mathrm{s}}$} & - & - \\
\hline P10 & 305.52 & 246.19 & 3.336 & {$[0 / 15 /-15 / 0 / 15 /-15]_{\mathrm{s}}$} & - & - \\
\hline P11 & 305.45 & 245.21 & 3.493 & {$[0 / 15 /-15 / 0 / 15 /-15]_{\mathrm{s}}$} & - & - \\
\hline P12 & 305.82 & 243.55 & 3.468 & {$[0 / 15 /-15 / 0 / 15 /-15]_{\mathrm{s}}$} & - & - \\
\hline P13 & 306.62 & 247.13 & 3.370 & {$[0 / 15 /-15 / 0 / 15 /-15]_{\mathrm{s}}$} & - & - \\
\hline P14 & 304.14 & 245.21 & 3.333 & {$[0 / 15 /-15 / 0 / 15 /-15]_{\mathrm{s}}$} & - & - \\
\hline
\end{tabular}

Table 2. Geometric data analysis $[\mathrm{mm}]$

\begin{tabular}{|c|c|c|c|c|c|}
\cline { 2 - 6 } \multicolumn{1}{c|}{} & \multicolumn{5}{c|}{ Stacking sequence } \\
\cline { 2 - 7 } \multicolumn{1}{c|}{} & \multicolumn{5}{c|}{$[0]_{8}$} \\
\cline { 2 - 7 } & Length & Width & Thickness & C1 & C2 \\
\hline Median & 305.00 & 245.34 & 2.176 & 3.923 & 4.324 \\
\hline St. Deviation & 0.50 & 0.54 & 0.018 & 0.251 & 0.598 \\
\hline Upper & 306.50 & 246.96 & 2.231 & 4.677 & 6.120 \\
\hline Lower & 303.50 & 243.71 & 2.120 & 3.168 & 2.527 \\
\hline Range & 2.99 & 3.25 & 0.110 & 1.508 & 3.592 \\
\hline Median & 305.67 & 245.21 & 3.341 & - & - \\
\hline Standard & 0.93 & 1.28 & 0.066 & - & - \\
\hline Upper & 308.48 & 249.06 & 3.538 & - & - \\
\hline Lower & 302.85 & 241.36 & 3.144 & - & - \\
\hline Range & 5.63 & 7.70 & 0.394 & - & - \\
\hline
\end{tabular}

Table 3. Nominal lamina material properties [25]

\begin{tabular}{|c|c|c|}
\hline \multicolumn{3}{|c|}{ Material Properties } \\
\hline Young's Modulus longitudinal. Direction $\left(\mathbf{E}_{\mathbf{1 1}}\right)$ & 127 & $\mathrm{GPa}$ \\
\hline Young's Modulus transversally. Direction $\left(\mathbf{E}_{\mathbf{2 2}}\right)$ & 10 & $\mathrm{GPa}$ \\
\hline Shear Modulus in plane 2-3 $\left(\mathbf{G}_{\mathbf{2 3}}\right)$ & 3.05 & $\mathrm{GPa}$ \\
\hline Poisson's ratio in plane 1-2 $\left(\mathbf{v}_{\mathbf{1 2}}\right)$ & 0.34 & - \\
\hline Shear Modulus in plane 1-2 $\left(\mathbf{G}_{\mathbf{1 2}}\right)$ & 5.4 & $\mathrm{GPa}$ \\
\hline
\end{tabular}


Table 4. Factors and its levels from $[0]_{8}$ plates considered for DoE analyses

\begin{tabular}{|c|c|c|c|}
\hline Factor & Level 1 & Level 2 & Unit \\
\hline Width $(\mathbf{W})$ & 243.71 & 246.96 & $\mathrm{~mm}$ \\
\hline Length (L) & 303.6 & 306.5 & $\mathrm{~mm}$ \\
\hline $\mathbf{C 1}$ & 3.17 & 4.68 & $\mathrm{~mm}$ \\
\hline $\mathbf{C 2}$ & 2.53 & 6.12 & $\mathrm{~mm}$ \\
\hline Theta(0 $\left.{ }^{\circ}\right)$ & -0.01 & 0.01 & degrees \\
\hline Thickness & 2.12 & 2.23 & $\mathrm{~mm}$ \\
\hline $\mathbf{E}_{\mathbf{1 1}}$ & 114.3 & 139.7 & $\mathrm{GPa}$ \\
\hline $\mathbf{E}_{\mathbf{2 2}}$ & 9.0 & 11.0 & $\mathrm{GPa}$ \\
\hline $\mathbf{G}_{\mathbf{2 3}}$ & 2.745 & 3.355 & $\mathrm{GPa}$ \\
\hline $\mathbf{v}_{\mathbf{1 2}}$ & 0.306 & 0.374 & \\
\hline $\mathbf{G}_{\mathbf{1 2}}$ & 4.86 & 5.94 & $\mathrm{GPa}$ \\
\hline
\end{tabular}

Table 5. Factors and its levels from $[0 / 15 /-15 / 0 / 15 /-15 / 0]_{s}$ plates considered for DoE analyses

\begin{tabular}{|c|c|c|c|}
\hline Factor & Level 1 & Level 2 & Unit \\
\hline Width (W) & 241.71 & 249.65 & $\mathrm{~mm}$ \\
\hline Length (L) & 301.34 & 309.99 & $\mathrm{~mm}$ \\
\hline $\boldsymbol{\theta ( \mathbf { 1 5 } ^ { \circ } )}$ & 14.0 & 16.0 & $\mathrm{~mm}$ \\
\hline $\boldsymbol{\theta ( - 1 5 ^ { \circ } )}$ & -14.0 & -16.0 & $\mathrm{~mm}$ \\
\hline $\boldsymbol{\theta}$ & -2.0 & 2.0 & degrees \\
\hline Thickness $^{\circ}$ & 3.16 & 3.45 & $\mathrm{~mm}$ \\
\hline $\mathbf{E}_{\mathbf{1 1}}$ & 114.3 & 139.7 & $\mathrm{GPa}$ \\
\hline $\mathbf{E}_{\mathbf{2 2}}$ & 9.0 & 11.0 & $\mathrm{GPa}$ \\
\hline $\mathbf{G}_{\mathbf{2 3}}$ & 2.745 & 3.355 & $\mathrm{GPa}$ \\
\hline $\mathbf{v}_{\mathbf{1 2}}$ & 0.306 & 0.374 & \\
\hline $\mathbf{G}_{\mathbf{1 2}}$ & 4.86 & 5.94 & $\mathrm{GPa}$ \\
\hline
\end{tabular}

Table 6. Resonance frequencies and damping coefficients

\begin{tabular}{|c|c|c|c|c|c|}
\hline \multicolumn{3}{|c|}{$[\mathbf{0}]_{\mathbf{8}}$} & \multicolumn{3}{|c|}{$[\mathbf{0 / 1 5 / - 1 5 / 0 / 1 5 / - 1 5 ]}$} \\
\hline \multirow{2}{*}{ Mode } & \multicolumn{2}{|c|}{ Damping } & \multirow{2}{*}{ Mode } & \multicolumn{2}{c|}{ Damping } \\
\cline { 2 - 3 } \cline { 5 - 6 } & Mean & Std. dev. & & Mean & Std. dev. \\
\hline 1 & $0.77 \%$ & $0.20 \%$ & 1 & $0.63 \%$ & $0.09 \%$ \\
\hline 2 & $0.53 \%$ & $0.05 \%$ & 2 & $0.58 \%$ & $0.03 \%$ \\
\hline 3 & $0.66 \%$ & $0.03 \%$ & 3 & $0.57 \%$ & $0.06 \%$ \\
\hline 4 & $0.76 \%$ & $0.09 \%$ & 4 & $0.66 \%$ & $0.12 \%$ \\
\hline 5 & $0.68 \%$ & $0.06 \%$ & 5 & $1.08 \%$ & $0.25 \%$ \\
\hline 6 & $1.06 \%$ & $0.32 \%$ & 6 & $0.44 \%$ & $0.03 \%$ \\
\hline 7 & $0.98 \%$ & $0.49 \%$ & \multicolumn{3}{|l}{} \\
\hline 8 & $0.51 \%$ & $0.03 \%$ & & & \\
\hline
\end{tabular}


Table 7. Numerical configurations layout of L12 table, Factor's level 1(low), Factor's level 2(high)

\begin{tabular}{|c|c|c|c|c|c|c|c|c|c|c|c|}
\hline & W & $\mathbf{L}$ & $\mathbf{C 1}$ & $\mathbf{C 2}$ & theta & $\mathbf{t}$ & $\mathbf{E}_{\mathbf{1 1}}$ & $\mathbf{E}_{\mathbf{2 2}}$ & $\mathbf{G}_{\mathbf{2 3}}$ & $\mathbf{v}_{\mathbf{1 2}}$ & $\mathbf{G}_{\mathbf{1 2}}$ \\
\hline Run1 & low & low & high & high & low & low & low & low & low & low & low \\
\hline Run2 & low & low & high & high & low & high & high & high & high & high & high \\
\hline Run3 & low & low & low & low & high & low & low & low & high & high & high \\
\hline Run4 & low & high & high & low & high & low & high & high & low & low & high \\
\hline Run5 & low & high & low & high & high & high & low & high & low & high & low \\
\hline Run6 & low & high & low & low & low & high & high & low & high & low & low \\
\hline Run7 & high & low & low & low & low & low & high & high & low & high & low \\
\hline Run8 & high & low & low & high & high & high & high & low & low & low & high \\
\hline Run9 & high & low & high & low & high & high & low & high & high & low & low \\
\hline Run10 & high & high & low & high & low & low & low & high & high & low & high \\
\hline Run11 & high & high & high & low & low & high & low & low & low & high & high \\
\hline Run12 & high & high & high & high & high & low & high & low & high & high & low \\
\hline
\end{tabular}

Table 8. Main effect results for stacking sequence $[0]_{8}$

\begin{tabular}{|c|c|c|c|c|c|c|c|c|c|c|}
\hline Factors & Mode1 & Mode2 & Mode3 & Mode4 & Mode5 & Mode6 & Mode7 & Mode8 & $\begin{array}{c}\text { Total Main } \\
\text { Effect [Hz] }\end{array}$ & Rank \\
\hline Thickness & 1.42 & 2.00 & 3.72 & 5.46 & 5.86 & 6.37 & 7.74 & 8.26 & 40.83 & 1 \\
\hline $\mathbf{E}_{\mathbf{2 2}}$ & 0.08 & 4.72 & 3.11 & 0.01 & 0.57 & 11.83 & 10.75 & 1.93 & 33.01 & 2 \\
\hline $\mathbf{E}_{\mathbf{1 1}}$ & 0.06 & 0.24 & 0.09 & 10.66 & 9.03 & 0.95 & 0.08 & 7.11 & 28.22 & 3 \\
\hline $\mathbf{G}_{\mathbf{1 2}}$ & 2.69 & 0.57 & 4.18 & 0.11 & 2.59 & 0.81 & 4.48 & 7.43 & 22.86 & 4 \\
\hline $\mathbf{C 2}$ & 0.04 & 3.36 & 0.38 & 0.10 & 0.23 & 3.80 & 0.79 & 0.67 & 9.38 & 5 \\
\hline $\mathbf{W}$ & -0.15 & -0.66 & -0.60 & -0.10 & -0.20 & -1.55 & -1.55 & -0.67 & -5.47 & 6 \\
\hline $\mathbf{L}$ & -0.16 & -0.11 & -0.29 & -1.15 & -1.18 & -0.19 & -0.38 & -1.09 & -4.55 & 7 \\
\hline $\mathbf{C 1}$ & 0.02 & 1.67 & 0.18 & -0.13 & 0.15 & 1.67 & 0.39 & 0.10 & 4.05 & 8 \\
\hline $\mathbf{v}_{\mathbf{1 2}}$ & 0.02 & 0.05 & 0.15 & 0.05 & 0.10 & 0.23 & 0.34 & 0.40 & 1.35 & 9 \\
\hline $\mathbf{G}_{\mathbf{2 3}}$ & -0.01 & 0.14 & 0.00 & 0.09 & 0.02 & 0.29 & 0.07 & 0.16 & 0.76 & 10 \\
\hline $\boldsymbol{\theta}$ & -0.02 & -0.07 & 0.01 & -0.12 & -0.11 & 0.00 & 0.07 & -0.20 & -0.45 & 11 \\
\hline
\end{tabular}

Table 9. Main effect results for stacking sequence $[0 / 15 /-15 / 0 / 15 /-15]_{\mathrm{s}}$

\begin{tabular}{|c|c|c|c|c|c|c|c|c|c|c|}
\hline Factors & Mode1 & Mode2 & Mode3 & Mode4 & Mode5 & Mode6 & Mode7 & Mode8 & $\begin{array}{c}\text { Total Main } \\
\text { Effect [Hz] }\end{array}$ & Rank \\
\hline Thickness & 9,28 & 12,57 & 22,84 & 27,72 & 29,42 & 38,62 & 44,53 & 48,69 & 233,67 & 1 \\
\hline $\mathbf{E}_{\mathbf{1 1}}$ & 4,70 & 0,35 & 8,19 & 30,77 & 18,18 & 13,52 & 10,61 & 31,73 & 118,05 & 2 \\
\hline $\mathbf{E}_{\mathbf{2 2}}$ & 0,49 & 13,05 & 7,99 & 0,57 & 12,10 & 25,54 & 27,33 & 7,60 & 94,67 & 3 \\
\hline $\mathbf{W}$ & $-3,54$ & $-9,20$ & $-10,90$ & $-0,14$ & $-13,06$ & $-16,66$ & $-24,92$ & $-14,80$ & $-93,22$ & 4 \\
\hline $\mathbf{L}$ & $-3,20$ & 0,03 & $-5,47$ & $-17,97$ & $-12,25$ & $-5,96$ & $-6,98$ & $-19,40$ & $-71,19$ & 5 \\
\hline $\mathbf{G}_{\mathbf{1 2}}$ & 5,81 & 0,90 & 10,09 & 1,28 & 5,52 & 4,44 & 12,82 & 18,41 & 59,28 & 6 \\
\hline $\boldsymbol{\theta ( - 1 5 )}$ & $-2,22$ & 0,70 & $-4,55$ & $-0,03$ & 3,64 & $-8,27$ & $-7,44$ & $-6,34$ & $-24,51$ & 7 \\
\hline $\boldsymbol{\theta ( 1 5 )}$ & 2,64 & 0,72 & 4,57 & $-2,16$ & 4,55 & $-0,56$ & 5,56 & 8,32 & 23,63 & 8 \\
\hline $\boldsymbol{\theta ( 0 )}$ & $-1,56$ & 0,09 & $-2,93$ & $-0,55$ & $-5,91$ & 5,11 & $-4,56$ & $-2,49$ & $-12,80$ & 9 \\
\hline $\mathbf{v}_{\mathbf{1 2}}$ & 0,27 & 0,62 & 1,12 & $-0,02$ & 0,68 & 1,99 & 2,54 & 1,72 & 8,92 & 10 \\
\hline $\mathbf{G}_{\mathbf{2 3}}$ & 0,41 & 0,13 & 0,63 & 0,26 & 3,79 & $-2,72$ & 1,52 & 0,73 & 4,75 & 11 \\
\hline
\end{tabular}


Table 10. Experimental results for intact and damaged plates, stack sequence [0]s.

\begin{tabular}{|c|c|c|c|}
\hline & \multicolumn{3}{|c|}{ Plate 1} \\
\hline & Intact & Damaged & Relative difference \\
\hline$f_{l}[\mathrm{~Hz}]$ & 61.89 & 64.20 & $3.74 \%$ \\
\hline$f 2[\mathrm{~Hz}]$ & 155.11 & 126.35 & $-18.54 \%$ \\
\hline$f_{3}[\mathrm{~Hz}]$ & 164.73 & 158.38 & $-3.86 \%$ \\
\hline$f_{4}[\mathrm{~Hz}]$ & 226.25 & 225.53 & $-0.32 \%$ \\
\hline$f_{5}[\mathrm{~Hz}]$ & 255.31 & 255.82 & $0.20 \%$ \\
\hline$f_{6}[\mathrm{~Hz}]$ & 332.95 & 336.24 & $0.99 \%$ \\
\hline$f_{7}[\mathrm{~Hz}]$ & 337.80 & 340.47 & $0.79 \%$ \\
\hline \multirow[t]{3}{*}{$f_{8}[\mathrm{~Hz}]$} & 362.87 & 351.66 & $-3.09 \%$ \\
\hline & \multicolumn{3}{|c|}{ Plate 3} \\
\hline & Intact & Damaged & Relative difference \\
\hline$f_{l}[\mathrm{~Hz}]$ & 60.21 & 59.42 & $-1.31 \%$ \\
\hline$f 2[\mathrm{~Hz}]$ & 153.08 & 118.92 & $-22.32 \%$ \\
\hline$f_{3}[\mathrm{~Hz}]$ & 158.53 & 140.65 & $-11.28 \%$ \\
\hline$f_{4}[\mathrm{~Hz}]$ & 224.79 & 222.72 & $-0.92 \%$ \\
\hline$f_{5}[\mathrm{~Hz}]$ & 250.44 & 247.92 & $-1.01 \%$ \\
\hline$f_{6}[\mathrm{~Hz}]$ & 324.99 & 320.26 & $-1.46 \%$ \\
\hline$f_{7}[\mathrm{~Hz}]$ & 328.69 & 327.63 & $-0.32 \%$ \\
\hline \multirow[t]{3}{*}{$f_{8}[\mathrm{~Hz}]$} & 354.21 & 338.70 & $-4.38 \%$ \\
\hline & \multicolumn{3}{|c|}{ Plate 4} \\
\hline & Intact & Damaged & Relative difference \\
\hline$f_{l}[\mathrm{~Hz}]$ & 62.52 & 63.48 & $1.53 \%$ \\
\hline $\mathrm{f}_{2}[\mathrm{~Hz}]$ & 154.46 & 135.61 & $-12.20 \%$ \\
\hline$f_{3}[\mathrm{~Hz}]$ & 161.77 & 155.02 & $-4.17 \%$ \\
\hline$f_{4}[\mathrm{~Hz}]$ & 221.16 & 223.00 & $0.83 \%$ \\
\hline$f_{5}[\mathrm{~Hz}]$ & 248.96 & 251.81 & $1.15 \%$ \\
\hline$f_{6}[\mathrm{~Hz}]$ & 328.05 & 331.37 & $1.01 \%$ \\
\hline$f_{7}[\mathrm{~Hz}]$ & 332.48 & 334.27 & $0.54 \%$ \\
\hline$f_{8}[\mathrm{~Hz}]$ & 355.77 & 353.19 & $-0.72 \%$ \\
\hline
\end{tabular}


Table 11. Experimental results for intact and damaged plates, stack sequence [0/15/-15/0/5/-15]s .

\begin{tabular}{|c|c|c|c|}
\cline { 2 - 4 } \multicolumn{1}{c|}{} & \multicolumn{3}{c|}{ Plate 9 } \\
\cline { 2 - 4 } \multicolumn{1}{c|}{} & Intact & Damaged & Relative difference \\
\hline$f_{1}[\mathrm{~Hz}]$ & 95.379 & 98.904 & $3.70 \%$ \\
\hline$f_{2}[\mathrm{~Hz}]$ & 132.911 & 134.096 & $0.89 \%$ \\
\hline$f_{3}[\mathrm{~Hz}]$ & 250.645 & 253.976 & $1.33 \%$ \\
\hline$f_{4}[\mathrm{~Hz}]$ & 316.229 & 315.735 & $-0.16 \%$ \\
\hline$f_{5}[\mathrm{~Hz}]$ & 349.436 & 353.229 & $1.09 \%$ \\
\hline$f_{6}[\mathrm{~Hz}]$ & 405.460 & 402.610 & $-0.70 \%$ \\
\hline & & \multicolumn{3}{c|}{ Plate 10} \\
\cline { 2 - 4 } & \multirow{2}{*}{ Intact } & Damaged & Relative difference \\
\hline$f_{1}[\mathrm{~Hz}]$ & 104.152 & 106.355 & $2.12 \%$ \\
\hline$f_{2}[\mathrm{~Hz}]$ & 139.884 & 140.295 & $0.29 \%$ \\
\hline$f_{3}[\mathrm{~Hz}]$ & 261.091 & 263.395 & $0.88 \%$ \\
\hline$f_{4}[\mathrm{~Hz}]$ & 320.690 & 320.133 & $-0.17 \%$ \\
\hline$f_{5}[\mathrm{~Hz}]$ & 367.079 & 369.029 & $0.53 \%$ \\
\hline$f_{6}[\mathrm{~Hz}]$ & 411.455 & 409.900 & $-0.38 \%$ \\
\hline & & \multicolumn{3}{c|}{ Plate 11} \\
\cline { 2 - 5 } & Intact & Damaged & Relative difference \\
\hline & 106.105 & 108.723 & $2.47 \%$ \\
\hline$f_{1}[\mathrm{~Hz}]$ & 145.625 & 145.531 & $-0.06 \%$ \\
\hline$f_{2}[\mathrm{~Hz}]$ & 265.984 & 268.152 & $0.82 \%$ \\
\hline$f_{3}[\mathrm{~Hz}]$ & 332.939 & 332.784 & $-0.05 \%$ \\
\hline$f_{4}[\mathrm{~Hz}]$ & 379.668 & 382.615 & $0.78 \%$ \\
\hline$f_{5}[\mathrm{~Hz}]$ & 429.651 & 427.393 & $-0.53 \%$ \\
\hline$f_{6}[\mathrm{~Hz}]$ & \multicolumn{3}{c|}{} \\
\hline
\end{tabular}


Table 12. Parameters used for full factorial analysis of plates

\begin{tabular}{|c|c|c|c|c|c|c|c|c|}
\hline & \multicolumn{5}{|c|}{$[\mathbf{0}]_{\mathbf{8}}$} & \multicolumn{4}{c|}{$[\mathbf{0 / 1 5 / - 1 5 / 0 / 5 / - 1 5}]_{\mathbf{s}}$} \\
\hline Run & $\begin{array}{c}\text { Thickness } \\
(\mathbf{m m})\end{array}$ & $\begin{array}{c}\mathbf{E}_{\mathbf{2 2}} \\
(\mathbf{G P a})\end{array}$ & $\begin{array}{c}\mathbf{E}_{\mathbf{1 1}} \\
(\mathbf{G P a})\end{array}$ & $\begin{array}{c}\mathbf{G}_{\mathbf{1 2}} \\
(\mathbf{G P a}\end{array}$ & $\begin{array}{c}\text { Thickness } \\
(\mathbf{m m})\end{array}$ & $\begin{array}{c}\mathbf{E}_{\mathbf{2 2}} \\
(\mathbf{G P a})\end{array}$ & $\begin{array}{c}\mathbf{E}_{\mathbf{1 1}} \\
(\mathbf{G P a})\end{array}$ & $\begin{array}{c}\mathbf{G}_{\mathbf{1 2}} \\
(\mathbf{G P a})\end{array}$ \\
\hline FRF1 & 2.12 & 9.0 & 114.3 & 4.86 & 3.16 & 9.0 & 114.3 & 4.86 \\
\hline FRF2 & 2.12 & 9.0 & 114.3 & 5.94 & 3.16 & 9.0 & 114.3 & 5.94 \\
\hline FRF3 & 2.12 & 9.0 & 139.7 & 4.86 & 3.16 & 9.0 & 139.7 & 4.86 \\
\hline FRF4 & 2.12 & 9.0 & 139.7 & 5.94 & 3.16 & 9.0 & 139.7 & 5.94 \\
\hline FRF5 & 2.12 & 11.0 & 114.3 & 4.86 & 3.16 & 11.0 & 114.3 & 4.86 \\
\hline FRF6 & 2.12 & 11.0 & 114.3 & 5.94 & 3.16 & 11.0 & 114.3 & 5.94 \\
\hline FRF7 & 2.12 & 11.0 & 139.7 & 4.86 & 3.16 & 11.0 & 139.7 & 4.86 \\
\hline FRF8 & 2.12 & 11.0 & 139.7 & 5.94 & 3.16 & 11.0 & 139.7 & 5.94 \\
\hline FRF9 & 2.23 & 9.0 & 114.3 & 4.86 & 3.45 & 9.0 & 114.3 & 4.86 \\
\hline FRF10 & 2.23 & 9.0 & 114.3 & 5.94 & 3.45 & 9.0 & 114.3 & 5.94 \\
\hline FRF11 & 2.23 & 9.0 & 139.7 & 4.86 & 3.45 & 9.0 & 139.7 & 4.86 \\
\hline FRF12 & 2.23 & 9.0 & 139.7 & 5.94 & 3.45 & 9.0 & 139.7 & 5.94 \\
\hline FRF13 & 2.23 & 11.0 & 114.3 & 4.86 & 3.45 & 11.0 & 114.3 & 4.86 \\
\hline FRF14 & 2.23 & 11.0 & 114.3 & 5.94 & 3.45 & 11.0 & 114.3 & 5.94 \\
\hline FRF15 & 2.23 & 11.0 & 139.7 & 4.86 & 3.45 & 11.0 & 139.7 & 4.86 \\
\hline FRF16 & 2.23 & 11.0 & 139.7 & 5.94 & 3.45 & 11.0 & 139.7 & 5.94 \\
\hline
\end{tabular}




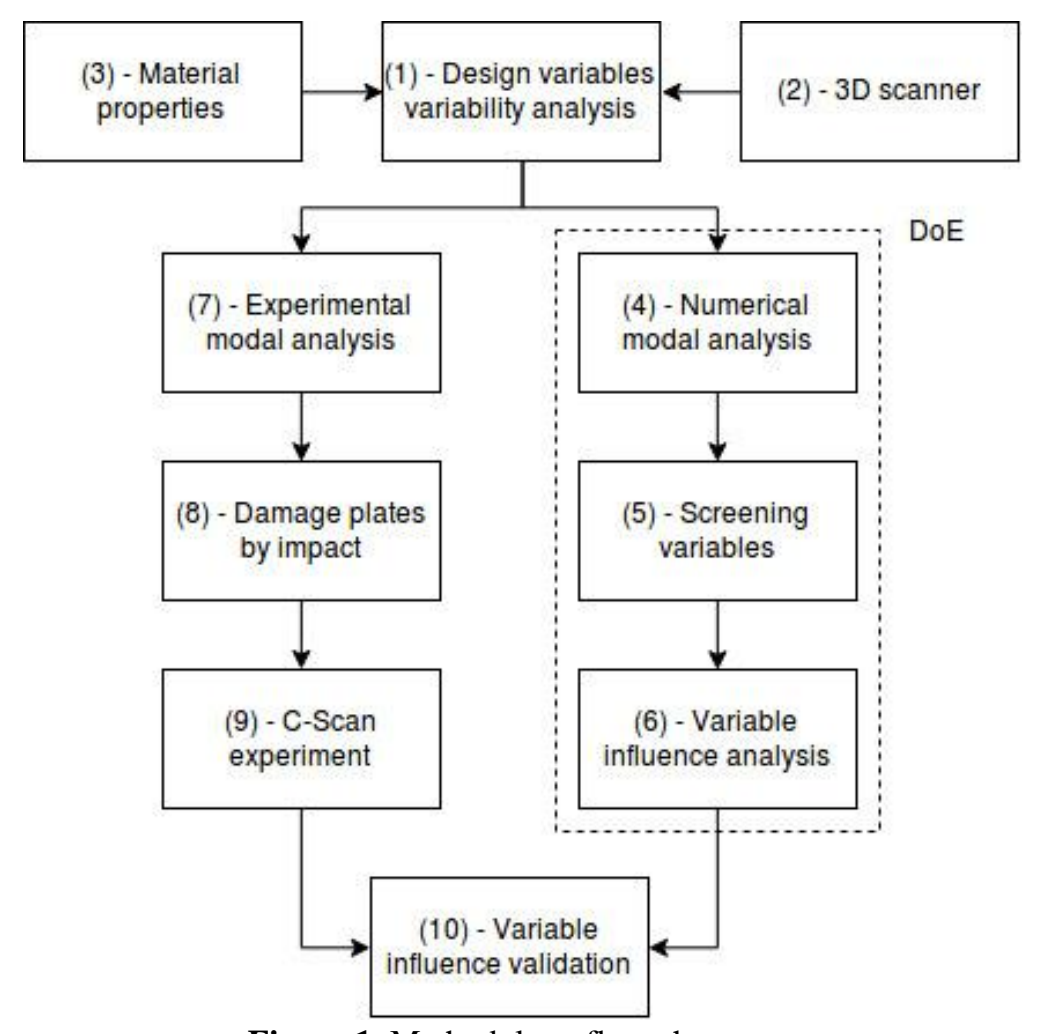

Figure 1. Methodology flow chart
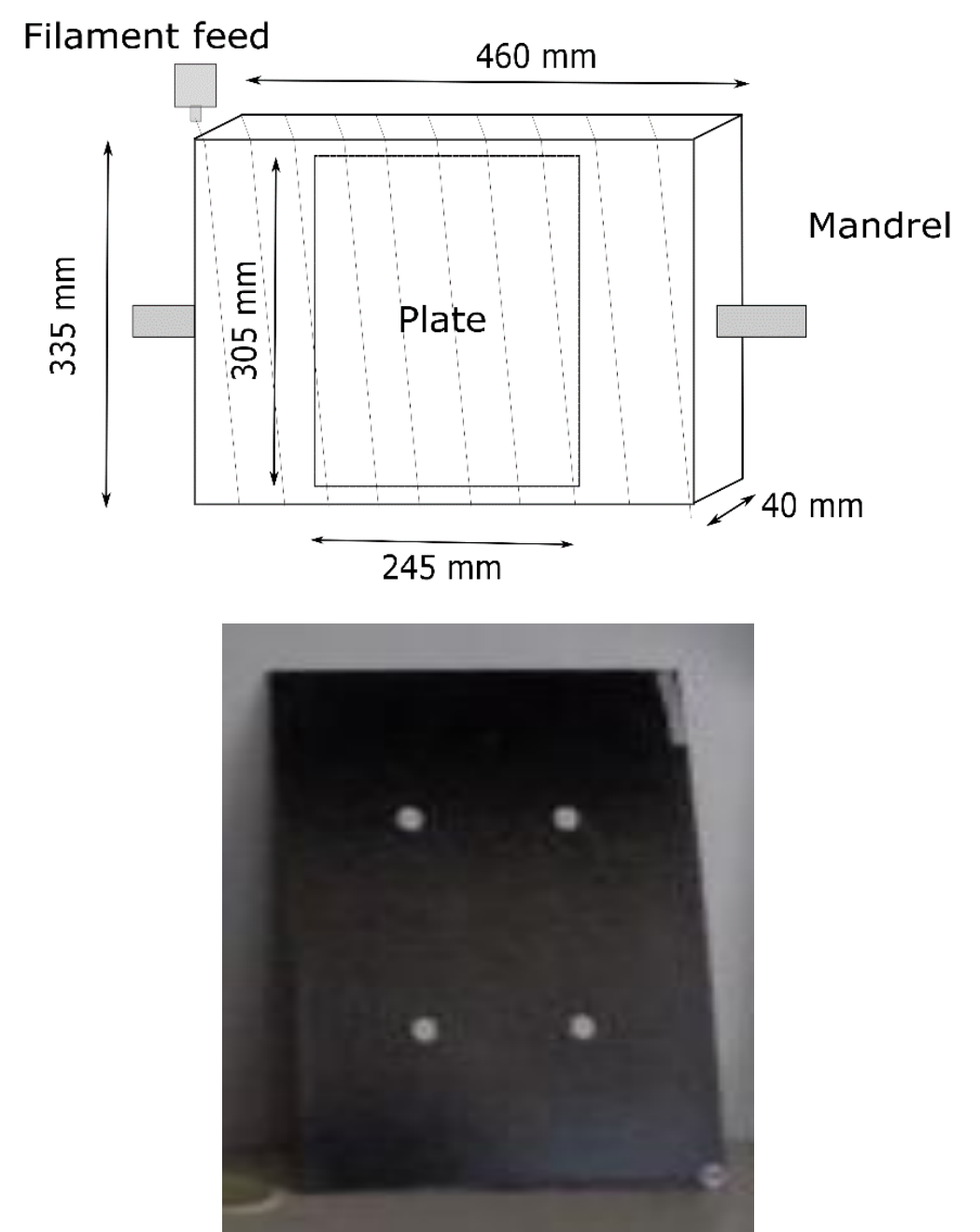

(a)

(b)

Figure 2. (a) Mandrel schematic and dimensions and, (b) Specimen used in experimental tests. 


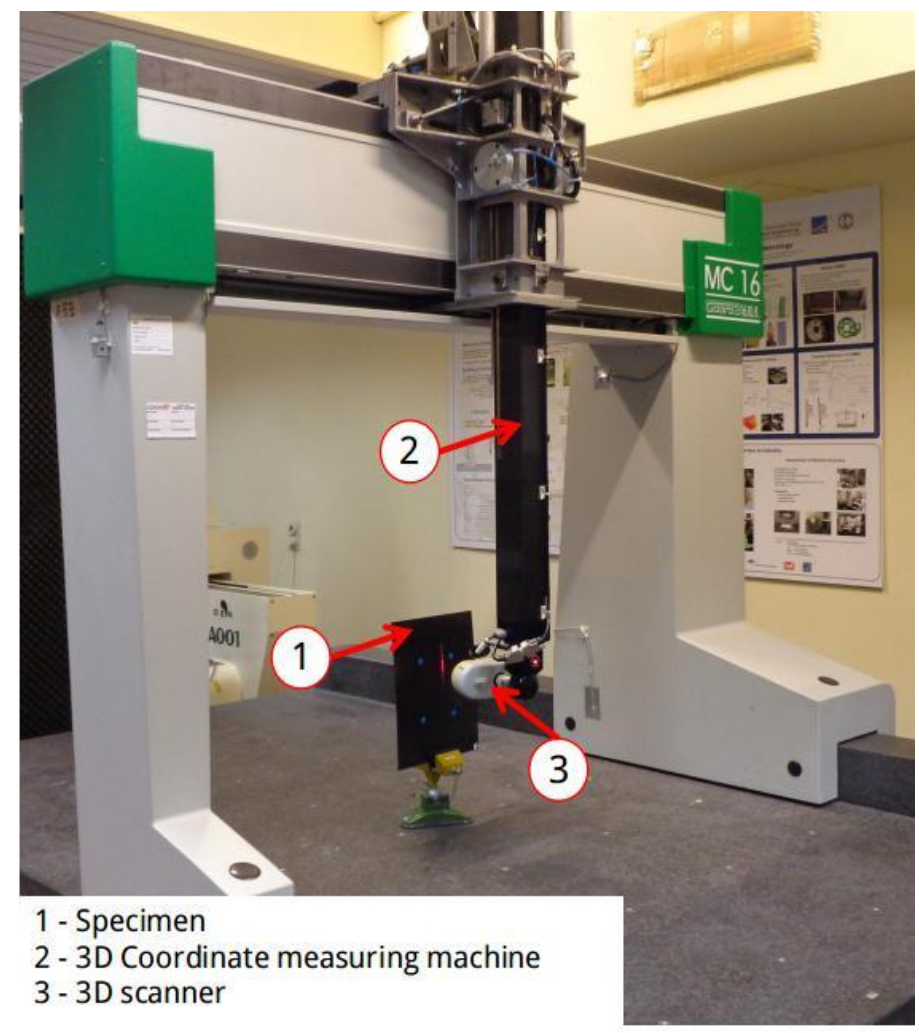

Figure 3. Coordinate machine with the 3D optical scanner.

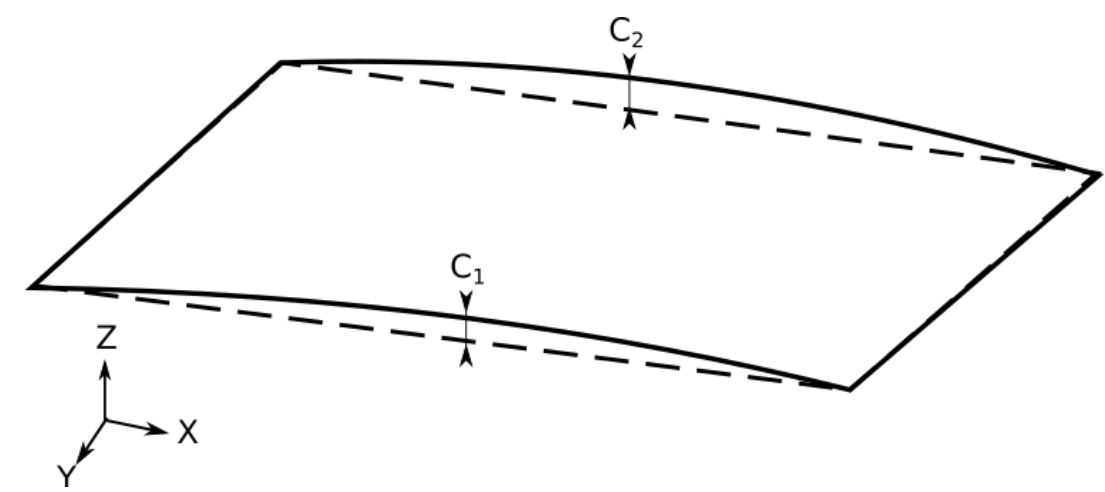

Figure 4. Specimen curvatures represented by the central distances $\mathrm{C} 1$ and $\mathrm{C} 2$ 


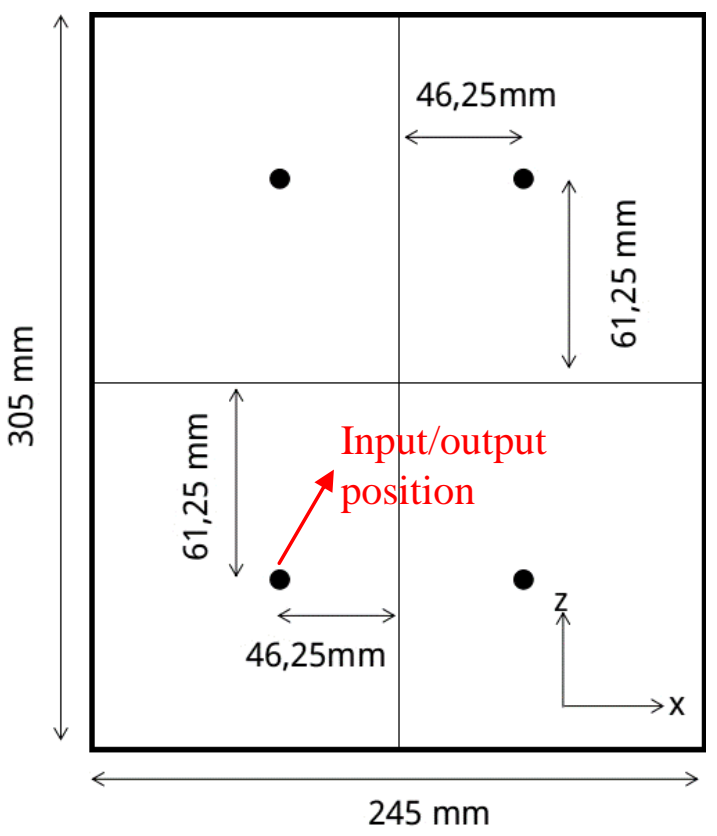

(a)

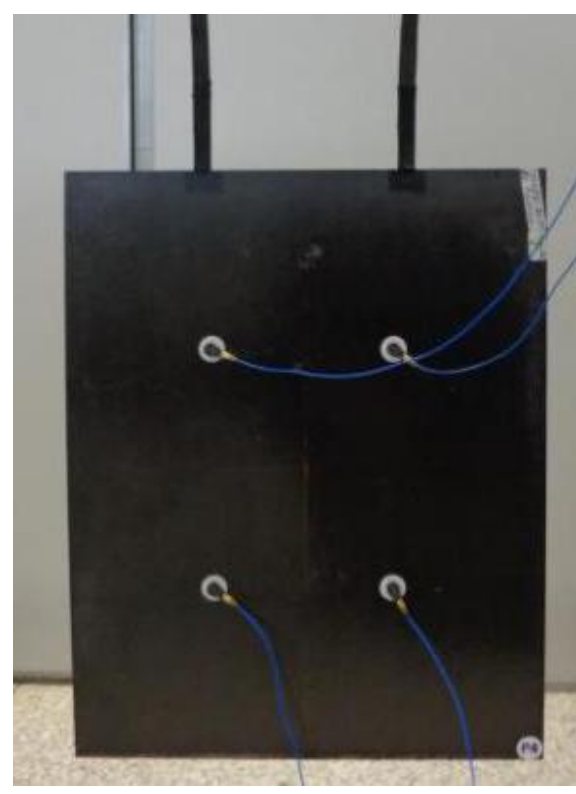

(b)

Figure 5. Specimen and accelerometers (a) schematic representation and (b) experimental analysis.

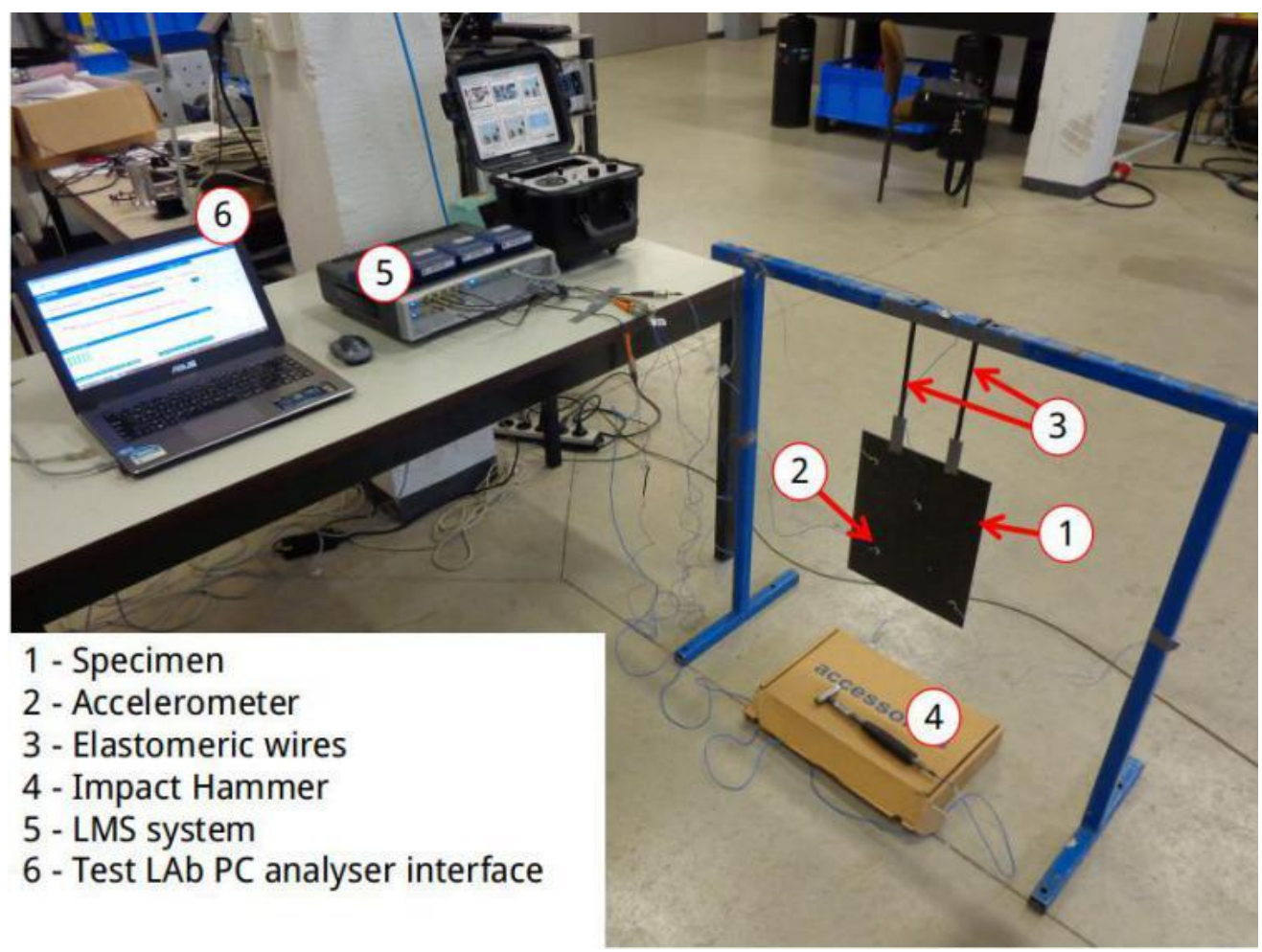

Figure 6. Experimental set-up 


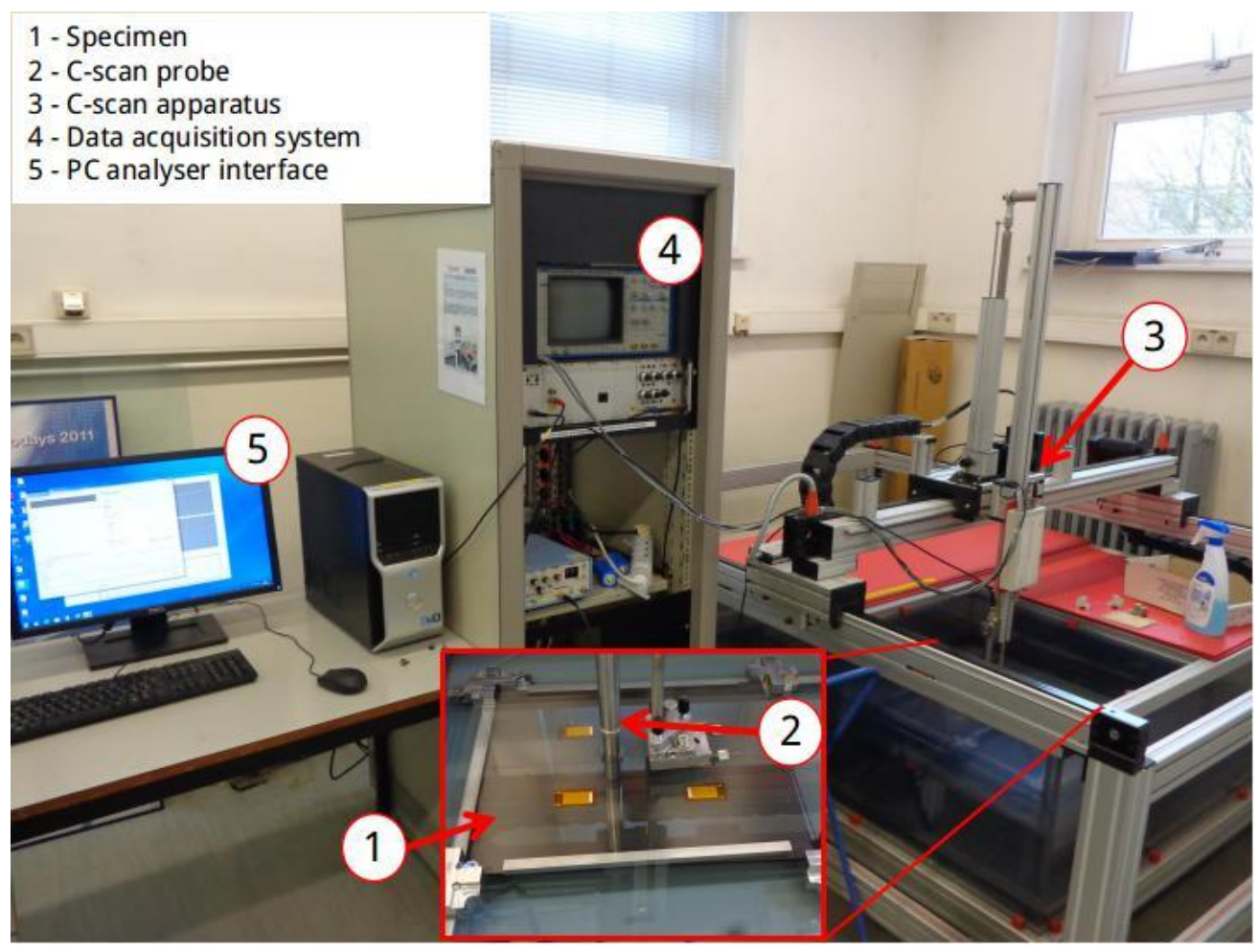

Figure 7. C-Scan test set up used for composite plates

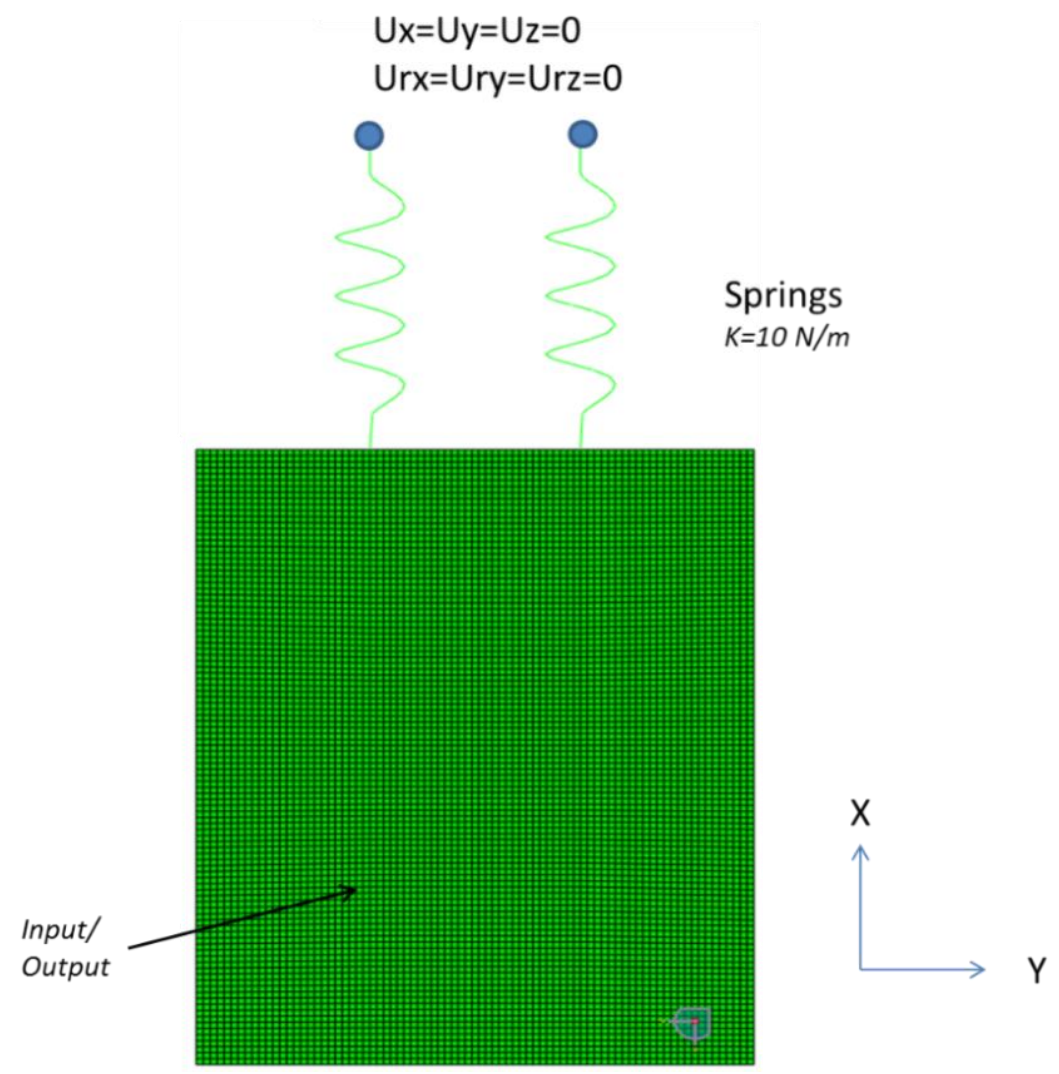

Figure 8. Finite element model 

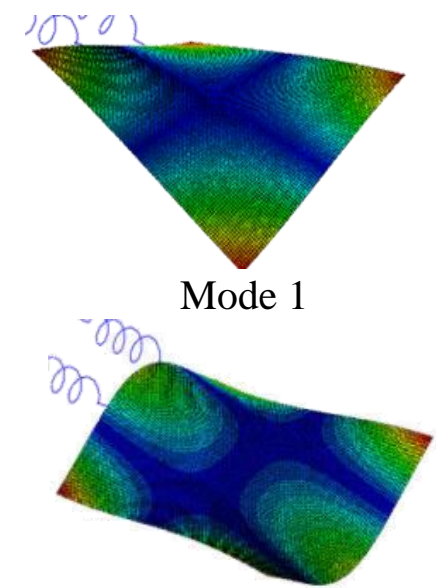

Mode 3

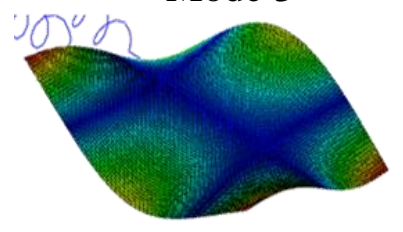

Mode 5

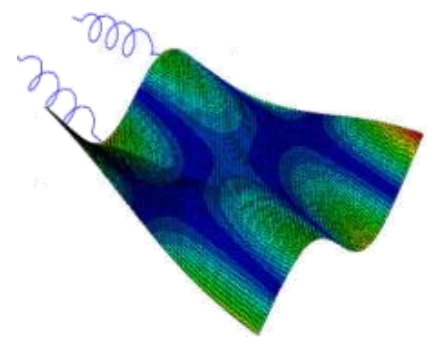

Mode 7

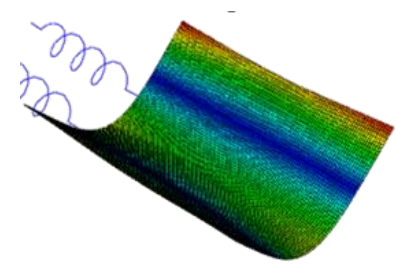

Mode 2

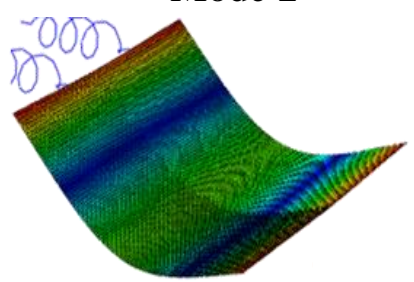

Mode 4

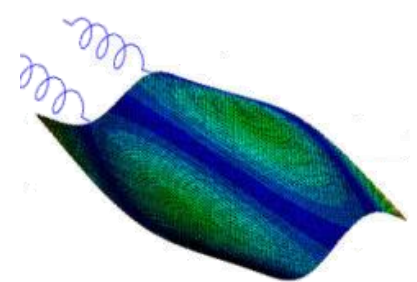

Mode 6

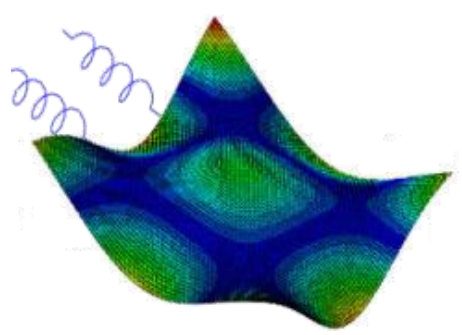

Mode 8

Figure 9. Mode shape of the plates $[0]_{8}$ and $[0 / 15 /-15 / 0 / 15 /-15 / 0]_{\mathrm{s}}$.

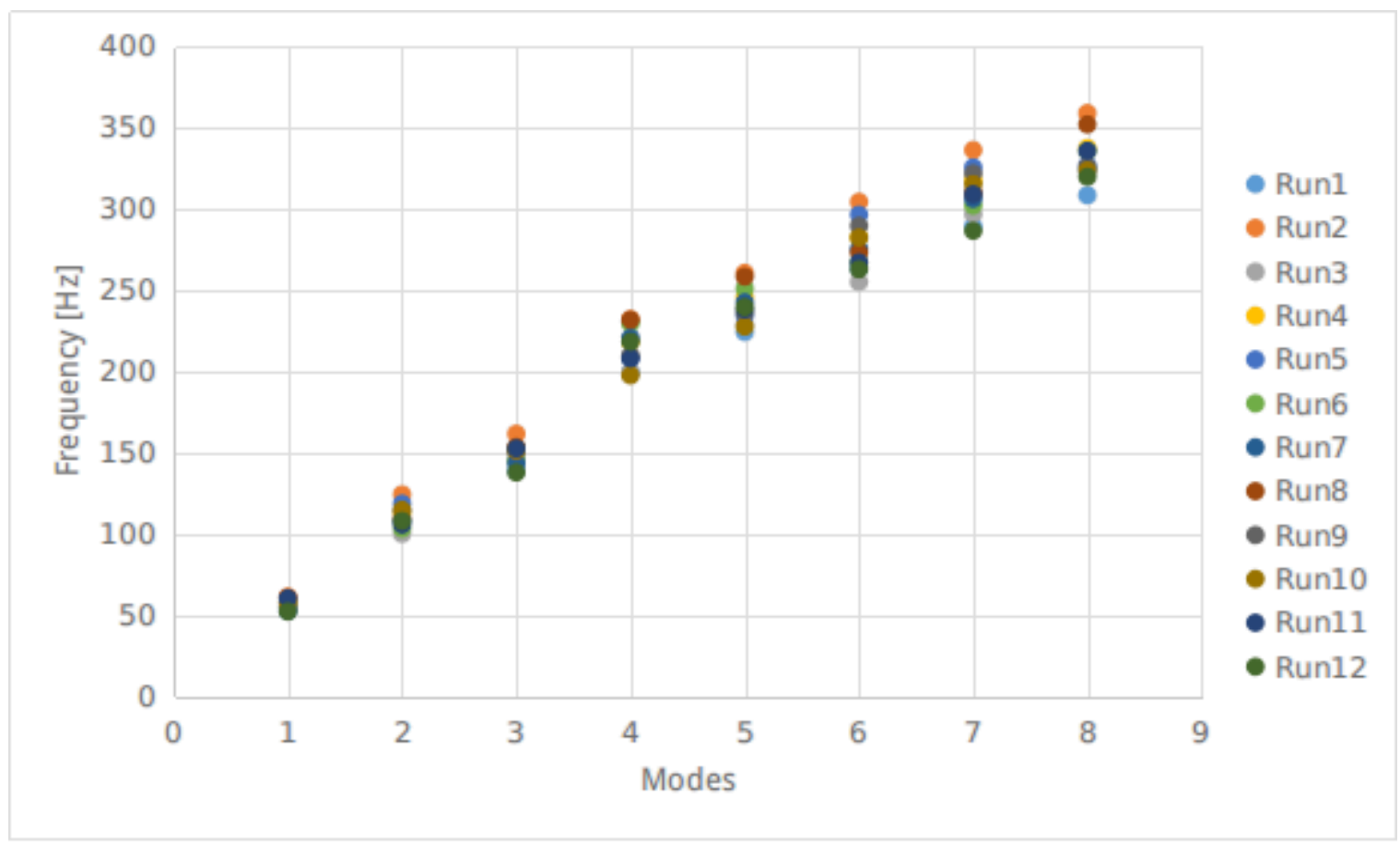

Figure 10. Natural frequencies resulted from the numerical modal analyses $[0]_{8}$ 


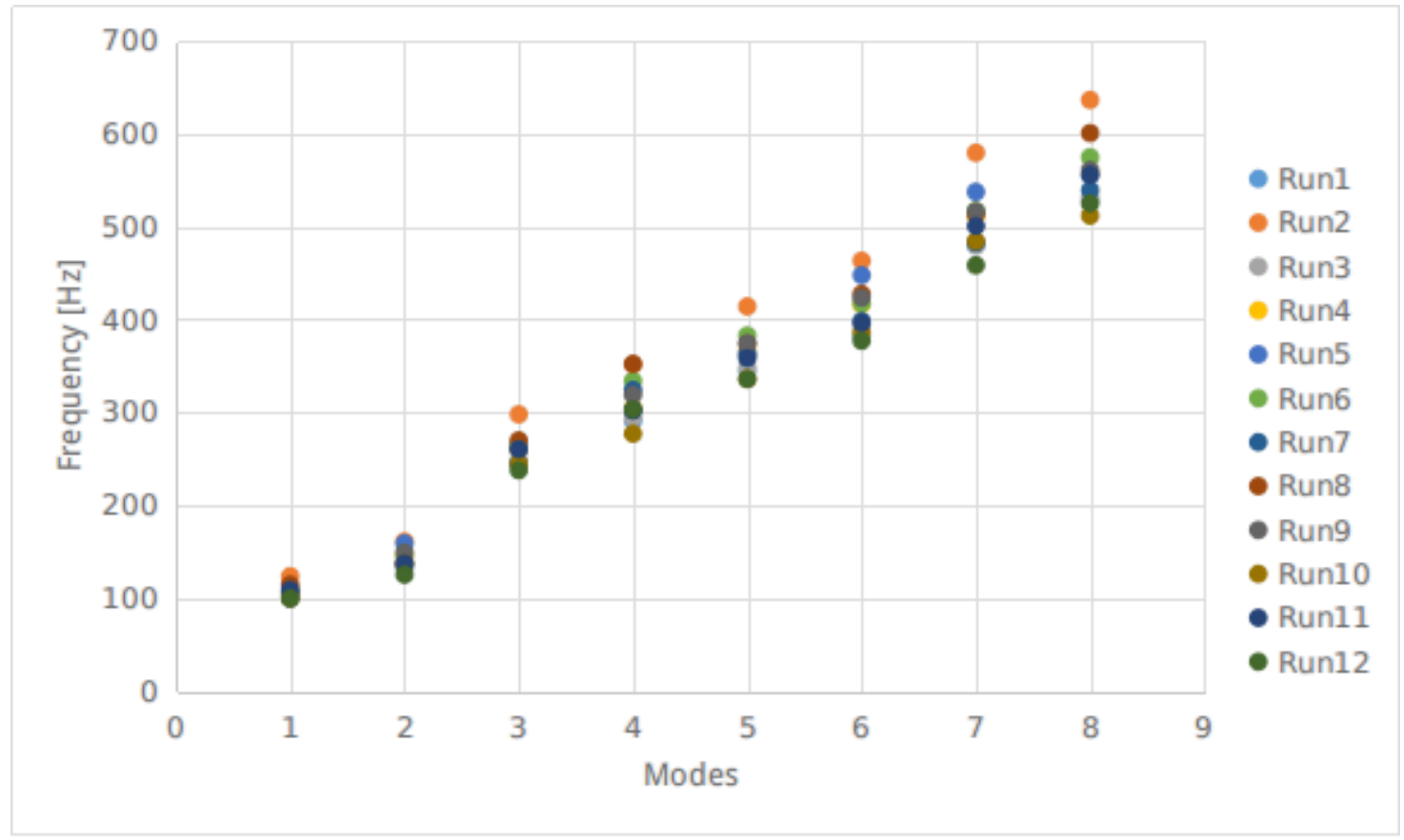

Figure 11. Natural frequencies resulted from the numerical modal analyses $[0 / 15 /-15 / 0 / 15 /-15 / 0]_{\mathrm{s}}$

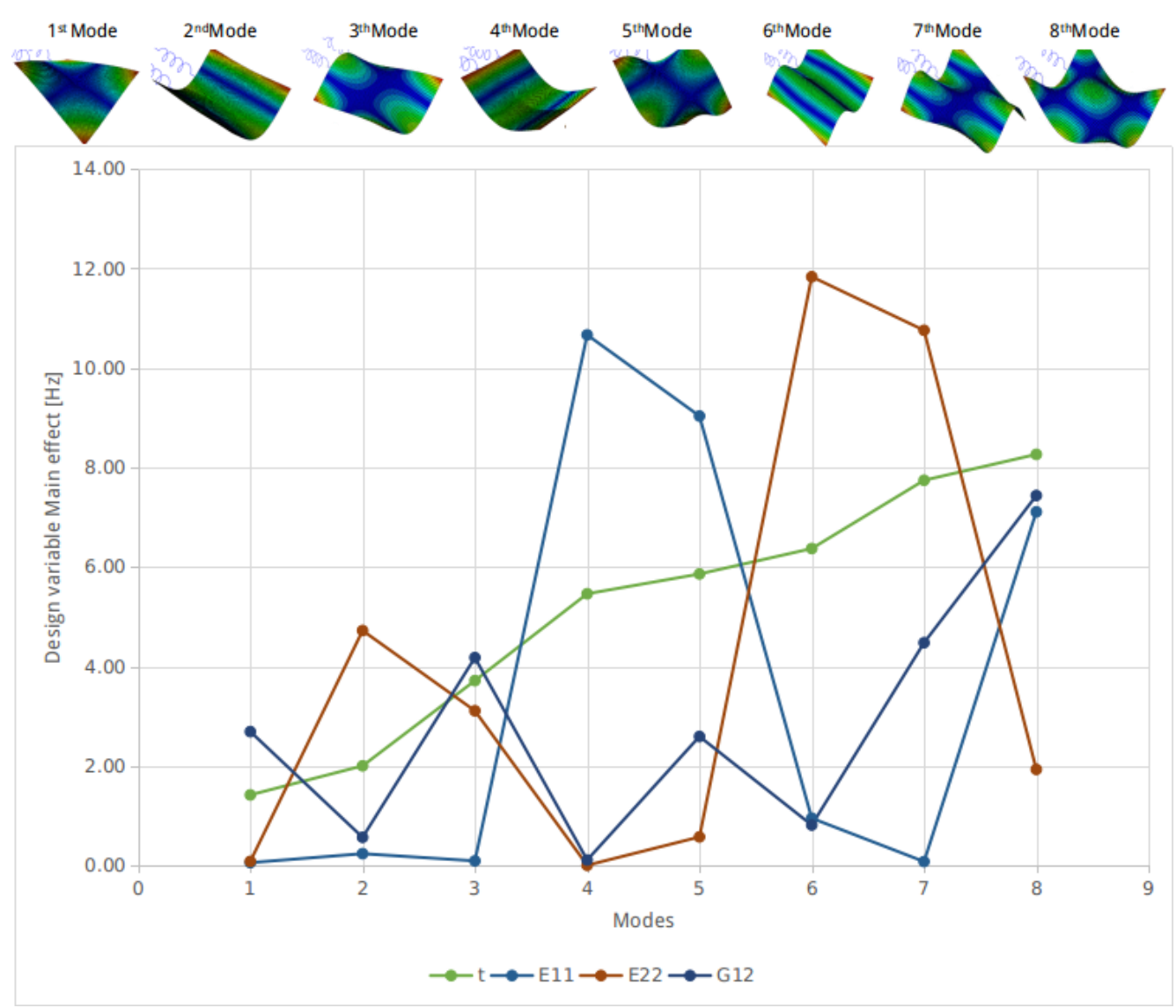

Figure 12. Main effect mode-by-mode $[0]_{8}$ 


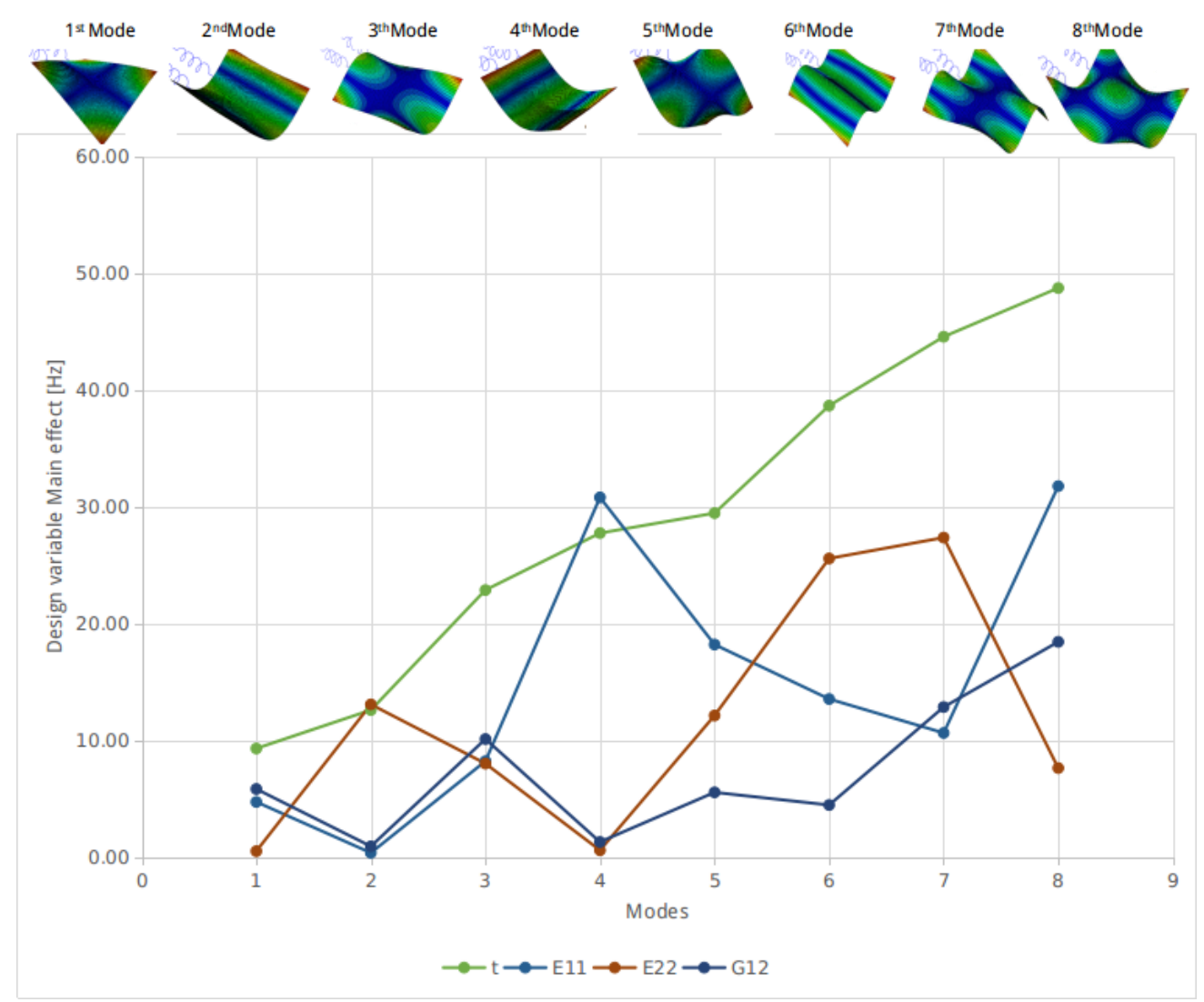

Figure 13. Main effect mode-by-mode $[0 / 15 /-15 / 0 / 5 /-15]_{s}$

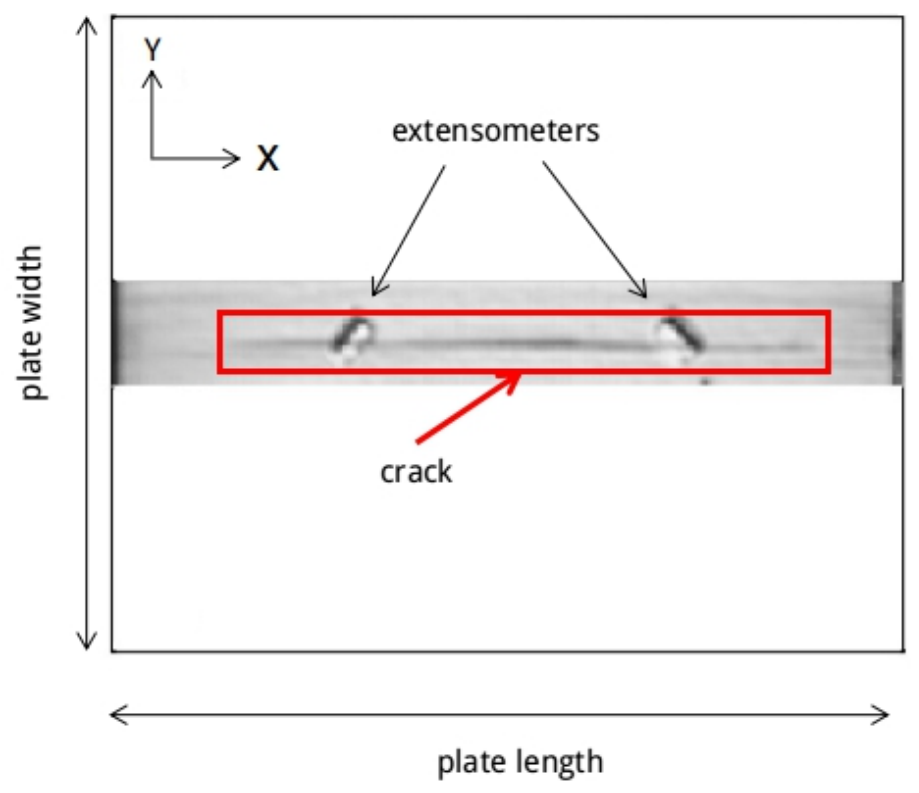

Figure 14. Damage observed by C-scan technique: $[0]_{8}$. Red box highlights the crack in the plate. 


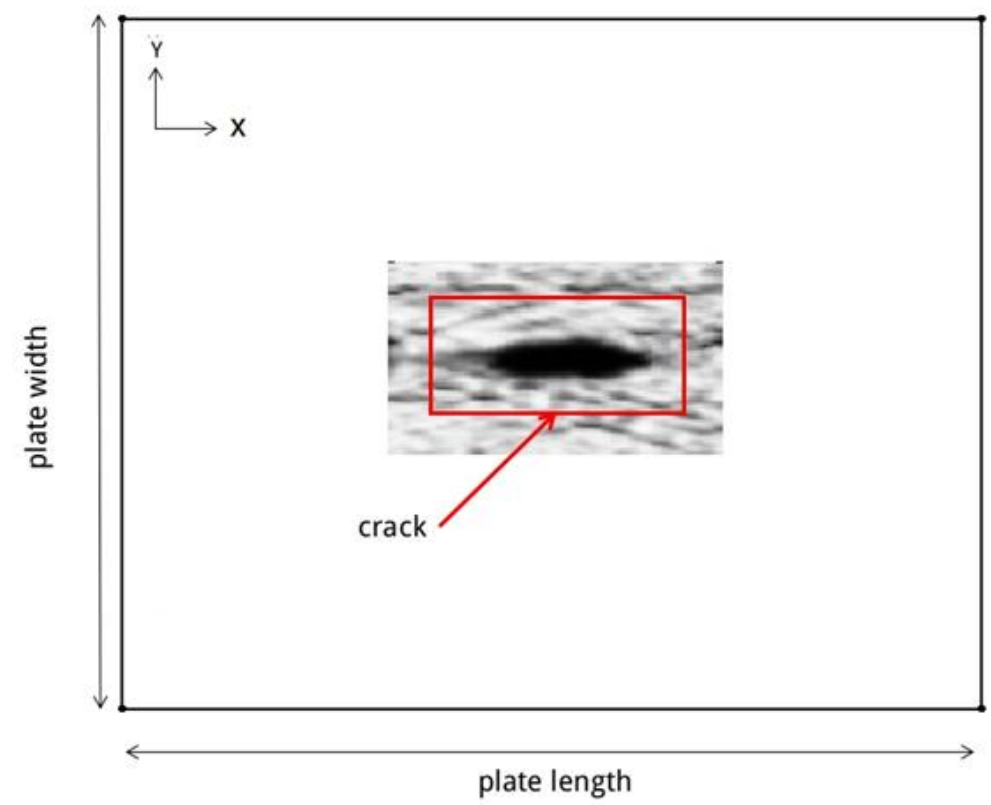

Figure 15. Damage observed by C-scan technique: [0/15/-15/0/5/-15]. Red box highlights the crack in the plate.

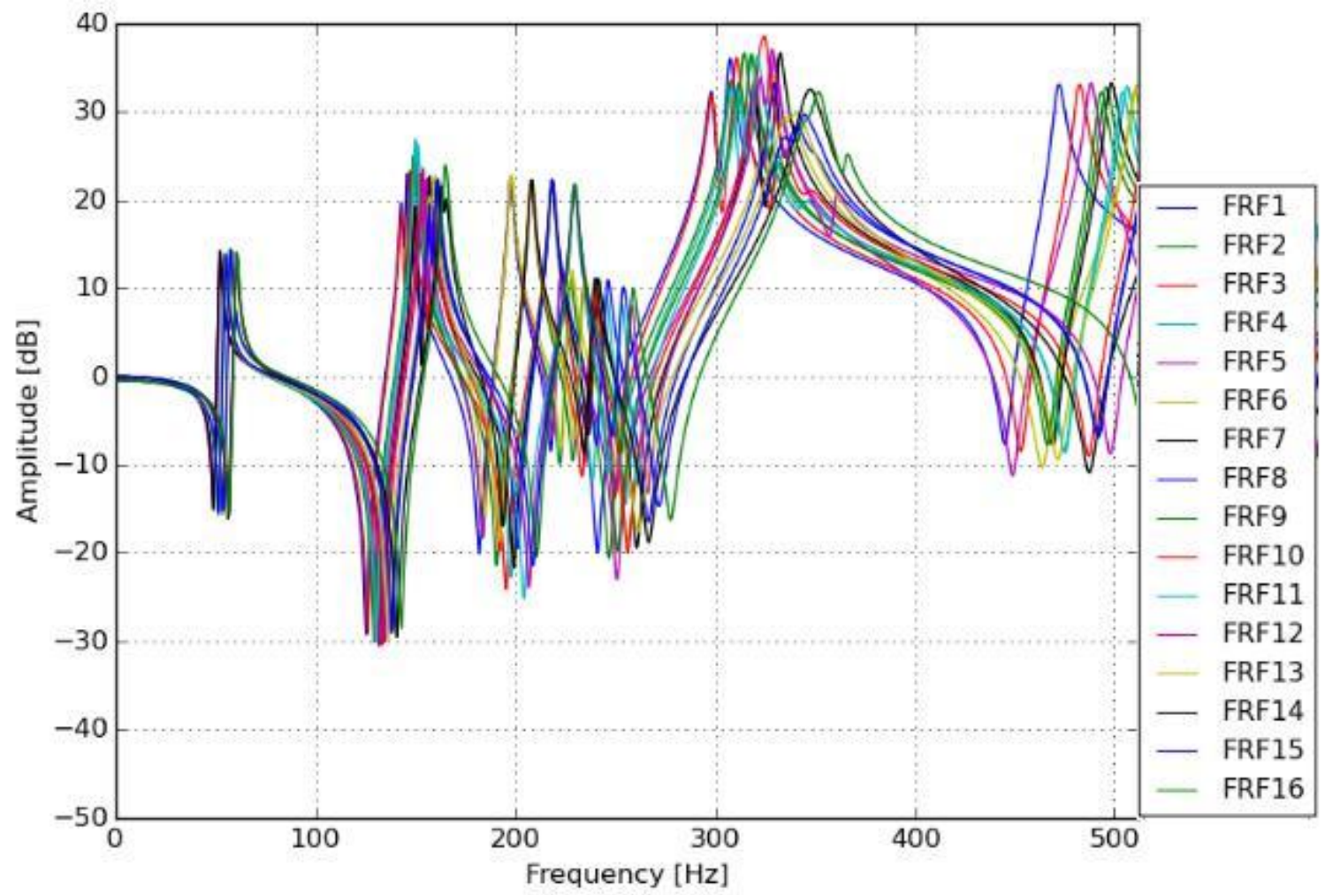

Figure 16. Numerical intact FRFs $[0]_{8}$ 


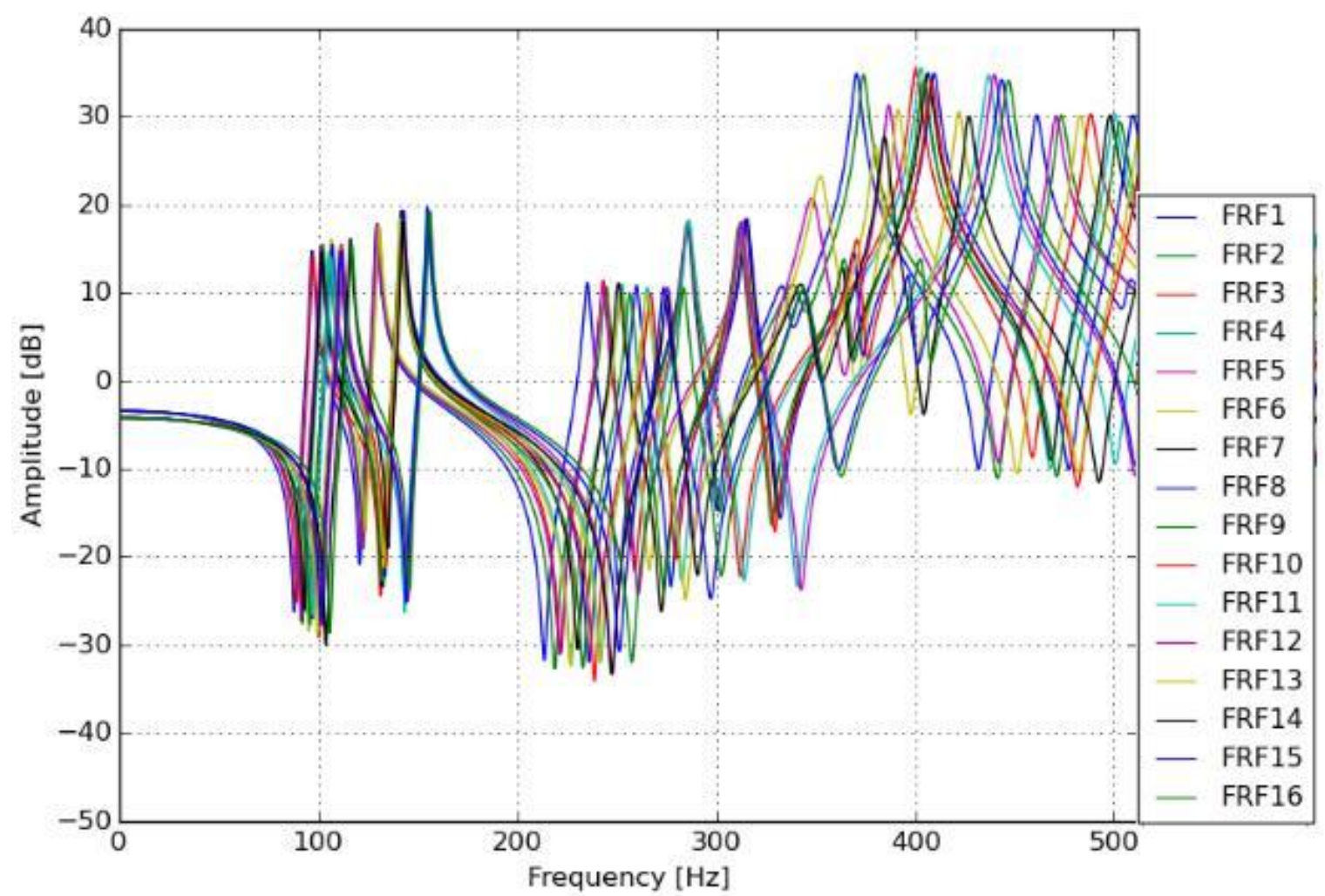

Figure 17. Numerical intact FRFs $[15 /-15 / 0 / 15 /-15 / 0]_{\mathrm{s}}$



Figure 18. FRF envelope: numerical and experimental (intact) results for $[0]_{8}$ 


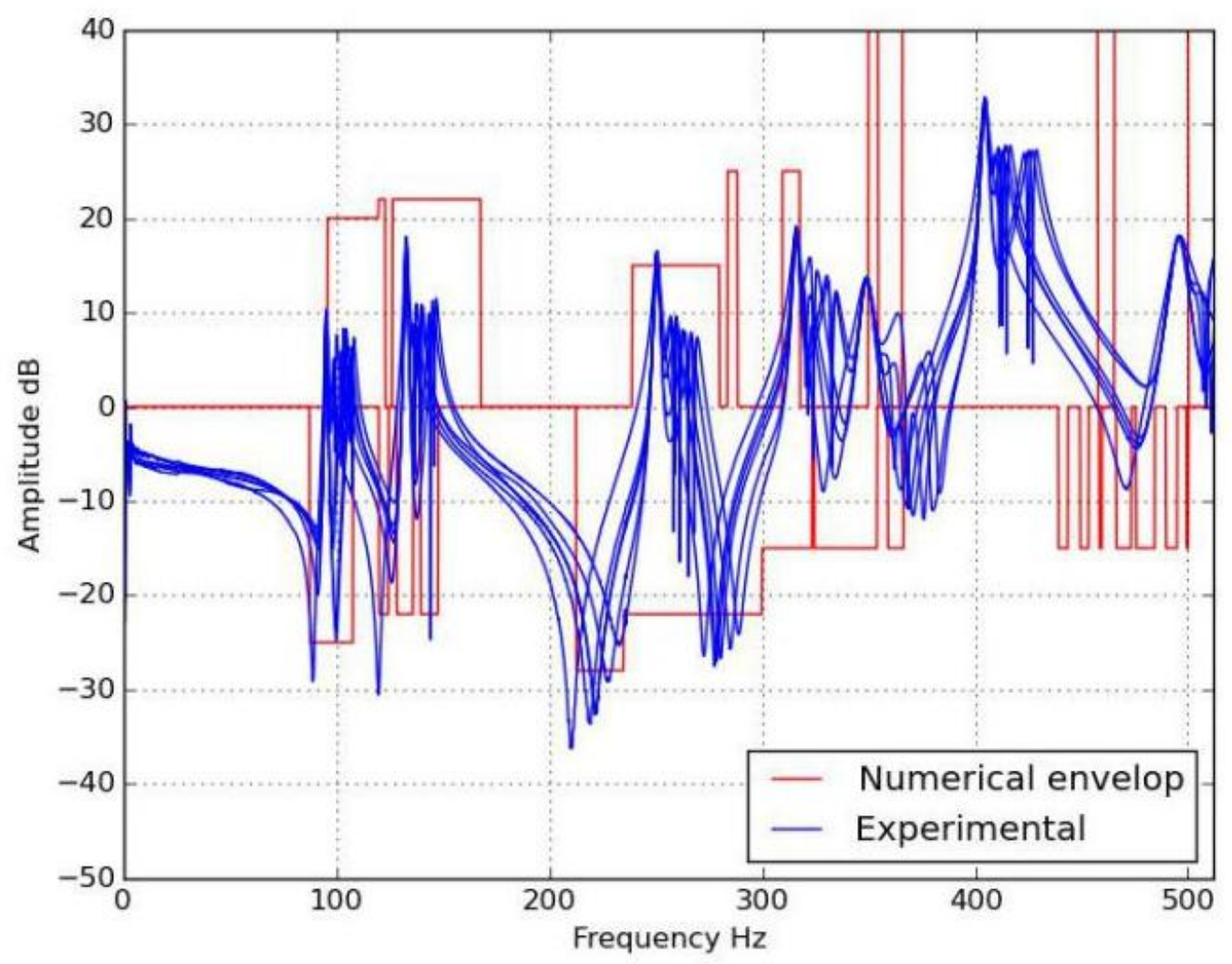

Figure 19. FRF envelope: numerical and experimental (intact) results for $[0 / 15 /-15 / 0 / 15 /-15 / 0]_{\text {s }}$ 